\title{
BARRAGENS DE CONTENÇÃO DE REJEITOS DE MINERAÇÃO NO BRASIL
}

\author{
T. F. SOUZA JUNIOR ${ }^{*}$, E. B. MOREIRA, K. S. HEINECK \\ Universidade Federal do Rio Grande do Sul \\ tennisonufpr@outlook.com*
}

Submetido 24/06/2018 - Aceito 01/11/2018

DOI: $10.15628 /$ holos. 2018.7423

\section{RESUMO}

O setor minerário brasileiro representa uma parcela importante na geração de recursos através da comercialização no mercado nacional e internacional. Este setor movimenta outros setores através do suprimento da matéria-prima extraída, como é exemplo das indústrias da construção civil, automobilística, aeroespacial e outras. Muito embora sua importância seja relevante e estratégica na economia, a geração de resíduos é significativa e para tanto é necessário que sejam viabilizados métodos de disposição destes materiais obedecendo as restrições ambientais, sociais e econômicas. Com isso, diante ao enorme vulto de materiais residuais gerados, as barragens de contenção rejeitos minerais representam uma das técnicas mais optadas por mineradoras e geotécnicos. Logo, este artigo tem como proposta fornecer informações quanto a conceitos, métodos construtivos, técnicas e outros aspectos que envolvam o assunto barragem de contenção de rejeitos a partir de uma revisão literária.

PALAVRAS-CHAVE: Barragem de rejeitos, métodos construtivos, técnicas construtivas, mineração, rejeitos minerais

\section{LITERARY REVIEW ON TAILINGS DAMS IN BRAZIL}

\begin{abstract}
The Brazilian mining sector represents an important part in the generation of resources through the commercialization in the national and international markets. This sector moves other sectors through the supply of raw materials, such as the civil construction, automobile, aerospace and other industries. Although its importance is relevant and strategic in the economy, the generation of waste is significant and for that it is necessary that methods of disposal of these materials
\end{abstract}

be made feasible obeying the environmental, social and economic restrictions. In view of the huge amount of waste materials generated, mineral retention dams represent one of the most preferred mining and geotechnical techniques. Therefore, this article aims to provide information on concepts, construction methods, techniques and other aspects that involve the subject dam retention from a literary review.

KEYWORDS: Tailings dam, construction methods, construction techniques, mining, mineral tailings 


\section{APRESENTAÇÃO}

O setor minerário possibilita a geração de um de volume na faixa de milhões de metros cúbicos de materiais extraídos e movimentados no processo de beneficiamento do minério. A quantidade de rejeito depende do processo utilizado na extração, da concentração da substância mineral estocada e da localização da jazida, muito embora a quantificação exata seja complexa devido à diversidade de operações e tecnologias utilizadas no processo de extração e beneficiamento.

Segundo dados do DNPM (2018), pôde-se notar uma expansão da atividade econômica da indústria extrativa. Entre os anos de 1995 e 2012, a produção extrativa mineral saiu 0,8\% para 4,3\% do PIB, reduzindo para 4,0\% do PIB no ano de 2014. Em 2014, o Brasil se destacou como o principal produtor de nióbio, com participação de $93,7 \%$ no mercado desse metal e ocupando o posto do segundo maior produtor de Magnesita, com 14,5\%. Outras substâncias minerais também mostraram elevada participação na produção mundial, tais como: crisotila $(15,6 \%)$, Manganês (15,3\%), Alumínio (14,9\%), Vermiculita (13,9\%), ferro (12,8\%), Tântalo (10,0\%), Talco e Pirofilita (9,2\%), Estanho (8,3\%) e Grafita (7,8\%).

A elevada produção dos rejeitos minerais advindos da etapa de beneficiamento do minério torna viável a construção de diques para estocagem deste material formando então as barragens de rejeitos. Entretanto, se construído ou concebido de forma inadequada, essas estruturas representam um grande risco para sociedade, meio ambiente e também para a economia.

Atualmente, no Brasil existem 839 barragens de rejeitos registradas, sendo a maioria (66\%) de pequeno porte (com volume total de reservatório inferior a 0,5 $\mathrm{hm}^{3}$ ) e concentrada no estado de Minas Gerais (43,5\%). No que tange aos critérios de riscos existentes, a maioria (aproximadamente 77\%) se encontra em categoria de risco baixo. Quanto ao dano potencial associado (DPA) $56,5 \%$ encontram-se baixo, porém $26,58 \%$ estão com dano potencial associado (DPA) elevado. (ANA, 2017)

Este trabalho tem como proposta apresentar os aspectos históricos, conceituais, métodos construtivos, técnicas de disposição e outras informações referentes a barragens de rejeitos minerais através de uma revisão literária.

\section{HISTÓRIA DAS BARRAGENS DE MINERAÇÃO}

Até o século $X V$, a geração de rejeitos pelas empresas de mineração e os impactos decorrentes de sua disposição no meio ambiente eram considerados desprezíveis. No entanto, com a introdução da força a vapor e com o aumento significativo da capacidade de processamento dos minerais de interesse econômico, a geração de rejeitos aumentou significativamente, sendo então encaminhados para os rios ou cursos d'água. (DUARTE, 2008; AVILA E SAWAYA, 2011)

Ávila e Sawaya (2011) citaram que as barragens de rejeitos no Brasil surgiram antes da corrida do ouro norte-americano, cuja atividade de mineração de ouro iniciou-se com a Mina de passagem, em Mariana. 
A partir do século $X V$, houve um avanço na técnica de mineração de materiais com baixo teor mineral, consequentemente, resultando na produção ainda maior de rejeitos, com granulometrias ainda menores. Entretanto, as práticas de disposição de rejeitos permaneceram inalteradas e, como resultado, mais rejeitos estavam sendo depositados e transportados por distâncias cada vez maiores das fontes geradoras para os cursos d'água, lagos e oceanos. (ÁVILA E SAWAYA, 2011)

Luz e Lins (2004) afirmaram que pela metade do século XIX, em 1864, o emprego do tratamento de minérios se limitava praticamente à produção de ouro, cobre nativo e chumbo. Além disso, os grandes desenvolvimentos na área de beneficiamento de minérios ocorreram no final do século XIX e início do século XX, sendo a utilização industrial da flotação, na Austrália, em 1905, a inovação mais impactante.

No início do sec. $X X$, começaram a surgir conflitos entre agricultores e mineradores, no Brasil, em decorrência da contaminação da água e obstrução de poços de irrigação que eram utilizados nas lavouras locais. Partindo disso, iniciaram a concepção das primeiras legislações referentes ao controle e gerenciamento dos rejeitos oriundos da atividade minerária. (DUARTE, 2008; ÁVILA E SAWAYA, 2011)

Cruz e Moretti (1996) comentaram que em meados do séc. XIX, muitas barragens de mineração foram construídas na Califórnia através da técnica de hidromecanização que, conforme reportado por Milonas (2006), através desta técnica os aterros são construídos hidraulicamente, ou seja, o processo está associado à exploração, transporte e distribuição de material por via úmida.

Para a manutenção da mineração e a mitigação dos impactos ambientais, as indústrias investiram na construção das primeiras barragens de contenção de rejeitos. As barragens construídas no início do século XIX geralmente eram projetadas transversalmente ao curso d'água, com considerações limitadas apenas para inundações. Consequentemente, quando fortes chuvas ocorriam, poucas destas barragens permaneciam estáveis e em muito poucas, ou mesmo nenhuma, havia engenheiros ou critérios técnicos envolvidos na fase de construção e operação. (DUARTE, 2008; ÁVILA E SAWAYA, 2011)

Até meados de 1930, equipamentos para movimentação de terras não eram acessíveis para a construção das barragens. Um pequeno dique era inicialmente preenchido com rejeitos hidraulicamente depositados e depois incrementado por pequenas bermas. Esse procedimento de construção, atualmente mecanizado, continua sendo utilizado. Uma década após isto, a disponibilidade de equipamentos de alta capacidade para movimentação de terras, especialmente em minas a céu aberto, tornou possível a construção de barragens de contenção de rejeitos com técnicas de compactação e maior grau de segurança, de maneira similar às barragens convencionais. (DUARTE, 2008; ÁVILA E SAWAYA, 2011)

Azam e Li (2010) comentam que durante as décadas de 1960, 1970 e 1980 houve um aumento significativo de construções de barragens de rejeitos pelo mundo, o que aproximadamente sextuplicou a quantidade de falhas de barragens de rejeitos por década. Atribui-se o aumento a extensa atividade de mineração imediatamente após a segunda Guerra Mundial, para atender à alta demanda global por metais, minerais e matérias-primas. Essa demanda estava relacionada à reconstrução pós-guerra na América do Norte e na Europa e ao desenvolvimento inicial de países recém-independentes no final do colonialismo na Ásia e na África.

O desenvolvimento da tecnologia para construção de barragens de contenção de rejeitos ocorreu de modo empírico, engrenado pelas práticas de construção e equipamentos disponíveis em cada época. Esse desenvolvimento ocorreu ainda sem a aplicação das técnicas da engenharia 
de barragens. Inclusive teve por muitos anos a aplicação de equipamentos de lavra, com orientação técnica dos engenheiros de minas, especializados nas técnicas de lavra. (DUARTE, 2008; ÁVILA E SAWAYA, 2011)

Ávila e Sawaya (2011) e Duarte (2008) citaram que o progresso das tecnologias de implantação de barragens de rejeitos foi impactado pelos acidentes com rupturas de barragens. Assim, na década de 50, muitos dos princípios fundamentais da Geotecnia já eram compreendidos e aplicados em barragens de contenção de rejeitos. Em 1965, um terremoto causou rompimento de muitas barragens de El Cobre no Chile que permitiu uma pressão popular ao poder público quanto leis que viessem estabelecer controle a estas estruturas.

Espósito (2000) citou que até 1960, quase todos os depósitos de rejeitos chilenos era barragens de rejeitos de linha de montante, usando o próprio rejeito como material de construção em aterros hidráulicos.

Na década de 70, a maioria dos aspectos técnicos (por exemplo, infiltração, liquefação e estabilidade da fundação) já eram bem entendidos e controlados pelos projetistas. Exemplos desta aplicação são as barragens de: Pontal, da Vale, em Itabira; Águas Claras, da então MBR Minerações Brasileiras Reunidas, em Nova Lima; e Germano, da Samarco, em Mariana. (DUARTE, 2008; ÁVILA E SAWAYA, 2011). No ano de 1970, o governo do Chile assinou o decreto 86 que regulamentava a construção e operação das barragens de rejeitos. (ESPÓSITO, 2000)

A partir da década de 80 , os aspectos ambientais também cresceram em importância. A atenção foi amplamente voltada para estabilidade física e econômica das barragens, considerando o potencial de dano ambiental e os mecanismos de transporte de contaminantes. (DUARTE, 2008; ÁVILA E SAWAYA, 2011)

Ávila (2012) detalhou toda formulação histórica, acidentes e demais informações a respeito da história de barragens de rejeitos no Brasil.

Na china, Wei et al. (2011) subdividiu a adoção de disposição de rejeitos em quatros fases: a) fase da baixa produção até 1958; b) Entre 1958 e 1978, caracterizada pela fase do crescimento da indústria nacional incentivado pelo governo chinês através da exploração das minas de ferro (Hainan e Anshan) e de estanho (Yunnan), cujos rejeitos eram descarregados diretamente em vales ou rios perto das minas; c) Entre os anos de 1978 e 2000, o número de instalações de disposição de rejeitos aumentaram constantemente, e o ambiente da mina mudou lentamente. O governo chinês promulgou a primeira lei de Proteção em 1989 e regulamentos relevantes em 1996, respectivamente; por fim, após os anos 2000 , onde houve um acelerado desenvolvimento da mineração e concomitante aumento de lagoas de decantação.

No Brasil, existiu um desenvolvimento lento da legislação voltada a barragem e o avanço de muitos aspectos das normas e leis aconteceram após ao rompimento da barragem de Fundão. Segundo CNDH (2017), no dia 5 de novembro de 2015, a barragem de Fundão, localizada na unidade industrial de Germano, no subdistrito de Bento Rodrigues, no Município de Mariana, na Região Central de Minas Gerais/Brasil, se rompeu, causando uma enxurrada de lama e rejeitos de mineração que provocou a destruição do subdistrito, deixou 17 mortos e mais de 600 desabrigadas e desalojadas, além dos demais impactos socioeconômicos e ambientais. De acordo com Fundaoinvestigation(2018) as causas se devem a um processo de liquefação estática devido a um recuo do eixo da crista e da ineficácia dos tapetes drenantes conforme a altura da barragem. 


\section{REJEITOS MINERAIS}

Espósito (2000) conceituou rejeitos como "resíduos resultantes de processos de beneficiamento, a que são submetidos os minérios visando extrair os elementos de interesse econômico (produto final) ". Araújo (2006) afirmou que sua constituição é caracterizada pela presença de uma fração líquida e sólida, com concentração de $30 \%$ a 50\% em peso. Estes materiais apresentam propriedades que são características do minério bruto e do processo industrial utilizado no beneficiamento.

Espósito (2000) comentou que os processos de beneficiamento têm como finalidade a regularização dos tamanhos dos fragmentos, remoção de minerais associados sem valor econômicos e melhora da qualidade.

Araújo (2006) afirmou que os rejeitos podem variar de materiais arenosos não plásticos (rejeitos granulares) até solos de granulometria fina e alta plasticidade (lamas). Quanto a composição granulométrica e consistência, geralmente os rejeitos de caráter granular são constituídos por areias finas a médias não plásticas, já as lamas são constituídas por siltes e argilas com alta plasticidade, difícil sedimentação e alta compressibilidade.

A Figura 1 ilustra toda a fase de tratamento de minério. Luz e Lins (2004) e Lozano (2006) explicam que o minério é extraído da jazida por meio de operações de lavra (a céu aberto ou subterrânea) na mina. O produto da mina, o minério lavrado, é frequentemente denominado ROM ("run-of-mine"), que vem a ser a alimentação da usina de beneficiamento.

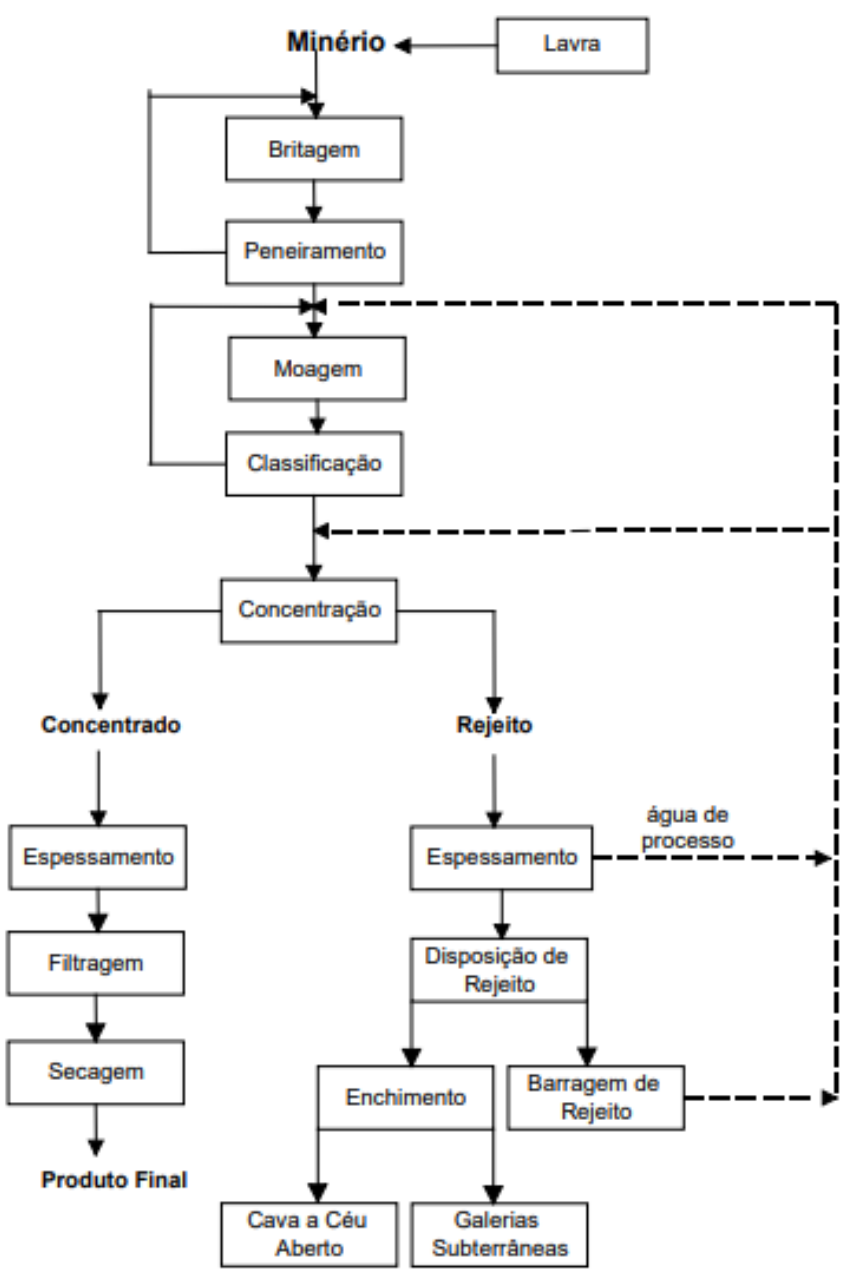


Figura 1: Fluxograma típico de tratamento de minério (Fonte: Luz e Lins, 2004).

Os mesmos comentam que a liberação do mineral ocorre através da operação de redução de tamanho através da cominuição, isto é, britagem e/ou moagem, que pode variar de centímetros até micrômetros. Salienta-se que há um alto custo envolvido no processo de moagem, operações de separação por tamanho ou classificação através de peneiramento, ciclonagem e outros.

A operação de concentração (separação seletiva de minerais) baseia-se nas diferenças de propriedades entre o mineral-minério (o mineral de interesse) e os minerais de ganga. Entre estas propriedades se destacam: peso específico (ou densidade), suscetibilidade magnética, condutividade elétrica, propriedades de química de superfície, cor, radioatividade, forma, etc. (LUZ E LINS ,2004)

Antes de se ter um produto para ser transportado ou mesmo adequado é necessário eliminar parte da água do concentrado. Estas operações compreendem desaguamento (espessamento e filtragem) e secagem. (LUZ E LINS ,2004). Araújo (2006) descreveu o processo de espessamento como uma remoção da água do rejeito para posterior recirculação na fase do beneficiamento.

É importante que o material transportado seja depositado na barragem de rejeitos minerais atendendo alguns critérios pois segundo Wang et al. (2014) nesta etapa forma-se um sedimento saturado em água e, na maioria das vezes, faz-se necessário expelir essa água em excesso para maior redução de volume e aumento da resistência mecânica do sedimento, satisfazendo as especificações regulatórias para deposição segura do rejeito. Niguyen e Borger (1998) afirmaram que a resistência mecânica referente a suspensão de sólidos finos pode ser caracterizada em termos de tensão de cisalhamento (resistência ao fluxo) e tensão de cedência compressiva (resistência à compressão), onde ambas crescem exponencialmente com o aumento do conteúdo sólido, sendo no caso das lamas vermelhas dependentes da mineralogia, granulometria e interações entre as partículas. Portanto, este processo possibilita que o depósito de rejeitos atinga condições estabilidade em menor tempo.

\subsection{Propriedades físicas do rejeito mineral}

Segundo Sarsby (2000), os rejeitos são geralmente angulares a muito angulares (exceto por areias betuminosas), areia volumosa granulada e partículas de tamanho de lodo. O tamanho das partículas e distribuição de tamanho de partícula de rejeitos e produtos industriais cobrem as faixas de produção e são influenciados pela matriz mineral.

O mesmo acrescentou que os rejeitos de rochas duras são dominados por areias (principalmente partículas de silicato finamente trituradas), e os lodos são derivados da rocha hospedeira esmagada, em vez da argila. Rejeitos grossos são aquelas características que são determinadas no todo, por frações de areia grossa de tamanho considerável. Quanto aos rejeitos finos, apresentam pouca ou nenhuma areia, incluem argilas fosfáticas, resíduos de bauxita, rejeitos finos de taconita e lamas de areias betuminosas.

Qiu e Sego (2001) realizaram ensaios de granulometria em quatro rejeitos e em termos de densidade real, obtiveram: 2,75 (Cobre), 3,17 (Ouro), 1,94 (Carvão Puro) e 2,60 (Compósito de areias de óleo em rejeitos consolidados).

Hu et al. (2017) realizaram caracterização física de quatros rejeitos, sendo eles: rejeitos finos e granulares de minério de ferro de Yuhezhai; e rejeitos finos e granulares de minério de cobre de Bahuerachi. Quanto a densidade real, os rejeitos finos e granulares de minério de ferro 
Yuhezhai apresentaram valores de 3,08 e 3,23, respectivamente. Já os rejeitos finos e granulares de minério de cobre de Bahuerachi apresentaram valores de 2,76 e 2,77, respectivamente.

Sarsby (2000) citou o comportamento das curvas granulometrias de seis rejeitos minerais (Bauxita, Carvão fino, Ouro, Cobre, Molibidênio e Trona), conforme Figura 2.

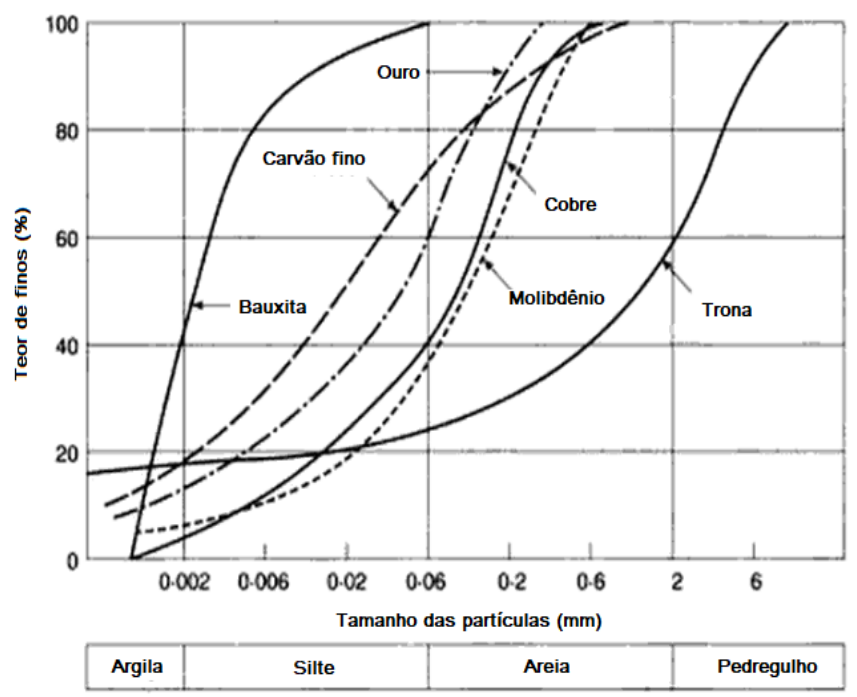

Figura 2: Curvas granulométricas de diferentes rejeitos minerais (Fonte: Sarsby, 2000).

Em termos de granulometria, de um modo geral, o teor de finos $(<74 \mu \mathrm{m})$ foram entre $21,2 \%$ e $81,3 \%$ e o teor de areia $(>0,06 \mathrm{~mm}$ ) foram entre $33,3 \%$ e $77 \%$. Pela classificação do Sistema Unificado de Classificação de Solo (USCS), os rejeitos receberam as nomenclaturas em termos de densidade real, obtiveram: SM (Cobre), ML (Ouro), CL (Carvão Puro) e SM (Compósito de areias de óleo em rejeitos. (QIU E SEGO, 2001)

Hu et al. (2017) citaram que com base nos resultados dos testes dos limites de Atterberg e distribuição granulométrica nos quatro rejeitos, os dois rejeitos grossos foram classificados como areia siltosa (SM), e os dois rejeitos finos são classificados como argila arenosa fina (CL) de acordo a USCS.

Sarsby (2000) citou que o tamanho do grão e o teor de argila controlam as taxas de vazios in situ, sendo que para as areias esses valores geralmente encontram-se na faixa de 0,6 a 1,1. Os lodos de argila altamente plástica ou composição incomum (principalmente argilas fosfáticas, bauxita e resíduos de areias oleosas) são propensos a ter altas taxas de vazios in situ, variando de cerca de 4 a 10, inclusive os mesmos podem apresentar baixas densidades in situ. A Tabela 1 anuncia alguns parâmetros físicos de determinados rejeitos minerais.

Tabela 1: Parâmetros de estado típicos de rejeitos minerais (Fonte: Adaptado de Sarsby, 2000)

\begin{tabular}{cccccc}
\hline Tipo & $*$ & $\delta$ real & e & $\rho_{s}\left(\mathrm{~g} / \mathrm{cm}^{3}\right)$ & $\begin{array}{c}\rho_{\mathrm{a}} \\
\left(\mathrm{g} / \mathrm{cm}^{3}\right)\end{array}$ \\
\hline Carvão & $\mathrm{L}$ & $1,4-2,1$ & $0,5-1,1$ & $0,7-1,4$ & $0,8-1,7$ \\
\hline Chumbo & $\mathrm{L}$ & $2,6-3,0$ & $0,6-1,1$ & $1,3-1,8$ & $1,7-2,2$ \\
\hline Molibdênio & $\mathrm{A}$ & $2,7-2,8$ & $0,7-0,9$ & $1,5-1,6$ & $1,6-1,8$ \\
\hline Cobre & $\mathrm{A}$ & $2,6-2,8$ & $0,6-0,8$ & $1,5-1,8$ & $1,8-1,9$ \\
& $\mathrm{~L}$ & $2,6-2,8$ & $0,9-1,4$ & $1,1-1,4$ & $1,5-1,9$ \\
\hline Hematita + & $\mathrm{A}$ & 3,0 & 0,7 & 1,8 & 1,9 \\
Magnetita & $\mathrm{L}$ & $3,1-3,3$ & $0,9-1,2$ & $1,5-1,7$ & $1,9-2,2$ \\
\hline
\end{tabular}




\begin{tabular}{cccccc}
\hline Bauxita & $\mathrm{L}$ & $2,8-3,3$ & 9 & 0,4 & 1,2 \\
\hline \multirow{2}{*}{ Trona } & $\mathrm{A}$ & $2,3-2,4$ & 0,7 & 1,5 & 1,7 \\
& $\mathrm{~L}$ & $2,4-2,5$ & 1,2 & 1,1 & 1,6 \\
\hline Fosfato & $\mathrm{L}$ & $2,5-2,8$ & 11 & 0,22 & 1,1 \\
\hline
\end{tabular}

Onde: $\delta$ real $=$ densidade real; $\mathrm{e}=$ índice de vazios; $\rho_{\mathrm{s}}=$ massa específica seca; e $\rho_{\mathrm{a}}=$ massa específica aparente; ${ }^{*}=\mathrm{L}$ (Lodo) /A(Arenoso)

Espósito (2000) estabeleceu a determinação da densidade dos grãos em função de valores de teores de ferro entre $11,44 \%$ e $72,40 \%$ :

$\rho_{s}=0,025 \% \mathrm{Fe}+2,6$

Onde:

$\rho_{s}$ : é a massa específica dos grãos;

\%Fe: Teor de ferro das amostras.

Santos e Ribeiro (2007) apresentaram resultados de ensaios em rejeitos de ferro realizados em campo, onde: a densidade dos grãos variou entre 2,95 a 3,14; os índices de vazios máximos variaram 0,88 a 1,00; e o índice de vazios mínimo entre 0,51 a 0,58 em pontos de furos ao longo da praia de rejeitos.

Kossof et al.(2014) elencaram as características físicas (granulometria, densidade real dos grãos e densidade aparente), químicas e mineralógicas de várias barragens de rejeitos estudadas por variados pesquisadores. Quanto as propriedades físicas, a densidade varia de acordo com o tipo de rocha, onde a faixa de densidade aparente do rejeito é 1,8 a $1,9 \mathrm{tf} / \mathrm{m}^{3}$ com uma densidade real dos grãos apresenta valores entre 2,6 a 2,8 tf/ $/ \mathrm{m}^{3}$.

Ainda segundo Kossof et al. (2014) a composição química dos rejeitos depende da mineralogia do corpo do minério, da natureza dos fluidos de processamento usados para extrair os metais economicamente, da eficiência do processo de extração e do grau de intemperismo durante o armazenamento no reservatório. As composições de elementos principais de rejeitos não são geralmente o foco da maioria dos estudos, cujos elementos são metálicos e metalóides potencialmente tóxicos. Sílica e a presença de ferro, no entanto, é quase universal e, junto com o oxigênio, são geralmente os elementos mais abundantes, com $\mathrm{Al}, \mathrm{Ca}, \mathrm{K}, \mathrm{Mg}, \mathrm{Mn}, \mathrm{Na}, \mathrm{P}, \mathrm{Ti}$ e $\mathrm{S}$ também componentes principais. Por fim, os rejeitos minerais podem ser divididos em três grandes categorias: a fração de ganga, a fração de óxido de sulfeto não econômica residual e a fração mineral secundária. Em rejeitos de sulfeto remanescente da extração de base e metais preciosos, a ganga fração é dominada pelo quartzo $\left(\mathrm{SiO}_{2}\right)$, e também pode compreender KFeldspato $\left(\mathrm{KAISi}_{3} \mathrm{O}_{8}\right)$, Na-feldspato $\left(\mathrm{NaAlSi}_{3} \mathrm{O}_{8}\right)$ e Ca-feldspato $\left(\mathrm{CaAl}_{2} \mathrm{Si}_{2} \mathrm{O}_{8}\right)$, Sericita $\left(\left(\mathrm{KAl}_{2}\right.\right.$ $\left.\left(\mathrm{AlSi}_{3} \mathrm{O}_{10}\right)(\mathrm{F}, \mathrm{OH})_{2}\right)$, clorito $\left((\mathrm{Mg}, \mathrm{Fe})_{3}(\mathrm{Si}, \mathrm{Al})_{4} \mathrm{O}_{10}(\mathrm{OH})_{2}(\mathrm{OH})_{6}\right)$, calcita $\left(\mathrm{CaCO}_{3}\right)$ e dolomite $(\mathrm{Ca}, \mathrm{Mg}$ $\left.\left(\mathrm{CO}_{3}\right)_{2}\right)$.

O trabalho do Sarsby (2000) comentou outras peculiaridades a respeito das propriedades físicas. Além desse, outras referências complementares podem ser citadas como estudos de barragens suecas e Volpe (1979); Bjelkevik e Knutsson (2005) e Shamsai et al. (2007).

\subsection{Permeabilidade dos rejeitos minerais}


Sarsby (2000) citou que o coeficiente de permeabilidade dos rejeitos minerais pode variar amplamente devido à variabilidade de classificação e densidade in situ. A permeabilidade média dos rejeitos abrange cinco ou mais ordens de grandeza, de cerca de $10^{-4} \mathrm{~m} / \mathrm{s}$ para rejeitos de areia limpos e grosseiros a $10^{-9} \mathrm{~m} / \mathrm{s}$ para argilas bem consolidadas. A Tabela 2 anuncia valores típicos de permeabilidade em função da natureza do material e pesquisadores.

Tabela 2: Valores de coeficientes de permeabilidade típicos de rejeitos minerais (Fonte: Sarsby, 2000)

\begin{tabular}{cccc}
\hline Material & Pesquisadores & $\mathrm{K}_{\mathrm{v}}(\mathrm{m} / \mathrm{s})$ & $\mathrm{K}_{\mathrm{h}}(\mathrm{m} / \mathrm{s})$ \\
\hline \multirow{3}{*}{ Arenosos } & Mittal \& Morgenstern (1975) & $2 \times 10^{-4} \mathrm{a} 9 \times 10^{-6}$ & - \\
\cline { 2 - 4 } & Genovis \& Tecca (1993) & $4 \times 10^{-5} \mathrm{a} 5 \times 10^{-6}$ & - \\
\cline { 2 - 4 } & Vick (1983) & $10^{-4} \mathrm{a} 10^{-9}$ & - \\
\hline \multirow{3}{*}{ Argilosos } & Genovis \& Tecca (1993) & $10^{-8} \mathrm{a} 5 \times 10^{-9}$ & - \\
\cline { 2 - 4 } & Routh (1984) - Argila da China & $5 \times 10^{-6} \mathrm{a} 5 \times 10^{-7}$ & $2 \times 10^{-5} \mathrm{a} \mathrm{5 \times 10^{-5 }}$ \\
\cline { 2 - 4 } & Routh (1984) - Tugstênio & $2 \times 10^{-7}$ & $10^{-6}$ \\
\cline { 2 - 4 } & Blight (1994) & $10^{-7} \mathrm{a} 10^{-9}$ & - \\
\hline
\end{tabular}

O mesmo salientou que a permeabilidade varia em função do tamanho das partículas, plasticidade, modo de deposição e profundidade. Além disso, sugere uma estimativa empírica de obtenção da permeabilidade através da formulação de Hazen anunciada pela equação (2):

$K=0,01 d_{10}^{2}$

Onde:

K: Coeficiente de permeabilidade;

$\mathrm{d}_{10}$ : Tamanho de $10 \%$ das partículas passantes.

Santos e Ribeiro (2007) apresentaram resultados de ensaios de permeabilidade com permeâmetro de Ghelph in situ em rejeitos de minério de ferro em campo, onde $\mathrm{K}$ variou de 7,68 $\times 10^{-3} \mathrm{~cm} / \mathrm{s}$ a $1,10 \times 10^{-2} \mathrm{~cm} / \mathrm{s}$ com amostras que variaram o teor de ferro (\%Fe) entre $13,88 \%$ a $21,64 \%$ e o índice de vazios entre 0,79 e 0,86.

Qiu e Sego (2001) realizaram a investigação em laboratório a partir de ensaios de condutividade hidráulica em quatro rejeitos e obtiveram: Cobre $\left(4,5 \times 10^{-5}\right.$ a $\left.9,8 \times 10^{-5} \mathrm{~cm} / \mathrm{s}\right)$; Ouro $\left(2,7 \times 10^{-5}\right.$ a $\left.6,7 \times 10^{-5} \mathrm{~cm} / \mathrm{s}\right)$; Carvão Puro $\left(4,0 \times 10^{-7}\right.$ a $\left.1,1 \times 10^{-5} \mathrm{~cm} / \mathrm{s}\right)$; e Compósito de areias de óleo em rejeitos consolidados $\left(2,2 \times 10^{-7}\right.$ a $\left.6,3 \times 10^{-7} \mathrm{~cm} / \mathrm{s}\right)$.

Sarsby (2000) afirmou que essa estimativa pode ser estendida para as lamas de rejeitos não plásticas e areias ciclonadas, muito embora nas lamas seja variável em detrimento da mudança de índice vazios.

Morris, Lockington e Apelt (2000) trouxeram comprovação disto através da relação entre o índice de liquidez e a permeabilidade normalizada em rejeitos de minas de carvão de New South Wales, bauxita de Western Austrália e argilas fosfatadas da Florida. Nesse estudo ele prova a permeabilidade aumenta com o aumento do índice de vazios.

Existem outros trabalhos que citam dados de permeabilidade de rejeitos minerais como por exemplo do Marcus (1997); Bjelkevik e Knutsson (2005); Shamsai et al. (2007) e Bhanbhro (2014), 


\subsection{Parâmetros de resistência dos rejeitos minerais}

Qiu e Sego (2001) realizaram a investigação em laboratório a partir de ensaios de CU de quatro rejeitos (Chumbo, Ouro, Carvão puro e rejeitos consolidados) foram obtidos valores entre $0 \mathrm{kPa}$ e $10 \mathrm{kPa}$ e ângulos de atrito entre $30^{\circ}$ e $34^{\circ}$. Hu et al. (2017) informou valores de ângulo de atrito e coesão através da Tabela 3 obtidos através de ensaios triaxiais CU e CD conduzidos nos rejeitos de ferro Yuhezhai $(A)$ e apenas ensaios triaxiais $C U$ conduzidos em rejeitos de cobre da Bahuerachi (B), cujos tipos são granulares $(G)$ e finos (F).

Tabela 3: Valores de ângulo de atrito e coesão obtidos através de ensaios CD e CU em minérios de ferro e CU em minério de cobre, na China. (Fonte: Hu et al., 2017)

\begin{tabular}{cccccccc}
\hline \multirow{2}{*}{ Tipos } & \multirow{2}{*}{ Tipo } & \multicolumn{9}{c}{$\mathrm{CU}$} & \multicolumn{2}{c}{$\mathrm{CD}$} \\
\cline { 2 - 8 } & & $\phi_{\mathrm{cu}}\left({ }^{\circ}\right)$ & $\mathrm{C}_{\mathrm{cu}}(\mathrm{kPa})$ & $\phi^{\prime}\left({ }^{\circ}\right)$ & $\mathrm{C}^{\prime}(\mathrm{kPa})$ & $\phi \mathrm{cd}\left({ }^{\circ}\right)$ & $\begin{array}{c}\mathrm{C}_{\mathrm{cd}} \\
(\mathrm{kPa})\end{array}$ \\
\hline \multirow{2}{*}{$\mathrm{A}$} & $\mathrm{G}$ & 25,0 & 194,0 & 41,0 & 8,8 & 40,0 & 30,1 \\
\hline \multirow{2}{*}{$\mathrm{B}$} & $\mathrm{F}$ & 16,0 & 13,8 & 32,0 & 7,4 & 35,0 & 28,5 \\
\cline { 2 - 8 } & $\mathrm{G}$ & 38,0 & 71,0 & 40,0 & 32,0 & - & - \\
\hline
\end{tabular}

Os valores $\varphi c_{u}$ e $c_{c u}$ denotam os parâmetros em termos de tensão total calculado a partir de ensaios CU; Os $\varphi^{\prime}$ e $c^{\prime}$ denotam os parâmetros em termos de tensão efetiva calculados a partir de ensaios $C U$ e por fim os $\varphi_{c d}$ e $c_{c d}$ denotam os parâmetros de tensão em termos de tensão efetiva calculados a partir de ensaios CD.

Vick (1990) elencou valores típicos de ângulo de atrito e tensão efetiva de vários tipos de rejeitos minerais (rejeitos granulares e finos de cobre; rejeitos granulares e finos de Taconite; rejeitos granulares e finos de Chumbo, Zinco e Prata; rejeitos finos de ouro; rejeitos finos de carvão; rejeitos finos de bauxita e rejeitos de gesso).

Existem outros estudos que citam permeabilidade de rejeitos minerais como os trabalhos de Marcus (1997); Bjelkevik e Knutsson (2005); Shamsai et al. (2007) e Bhanbhro (2014)

\subsection{Parâmetros de consolidação dos rejeitos minerais}

Sarsby (2000) citou que o coeficiente de consolidação primária $\left(C_{v}\right)$ de rejeitos arenosos ocorre tão rapidamente que é difícil medir, muito embora os dados disponíveis sugiram que o $C_{v}$ varie entre 1000 e $300.000 \mathrm{~m}^{2} /$ ano para depósitos de areia na praia. O mesmo citou que para rejeitos argilosos, o $C_{v}$ é geralmente cerca de 0,3 a $300 \mathrm{~m}^{2} /$ ano, o que está na mesma faixa que a exibida por solos argilosos convencionais.

Qiu e Sego (2001) realizaram a investigação em laboratório a partir de ensaios de consolidação baseados nos postulados de Head (1992) e obteve valores de $C_{v}$ entre 22,32 a $104,23 \mathrm{~m}^{2}$ / ano em rejeitos de cobre, 13,58 a 80,07 m²/ ano em rejeitos de ouro e 0,310 a 17,26 $\mathrm{m}^{2}$ /ano e rejeitos. Vick (1990) citou faixas de coeficiente de consolidação $\left(C_{v}\right)$ para depósitos de areia da praia e rejeitos de lodos obtendo valores de $5 \times 10^{-1}$ a $10^{2} \mathrm{~cm} / \mathrm{s}$ e $10^{-2}$ a $10^{-4} \mathrm{~cm} / \mathrm{s}$, respectivamente.

Quanto ao índice de compressão $\left(C_{c}\right)$, Sarsby (2000) citou que em rejeitos arenosos estes valores variavam entre 0,05 a 0,13 e nos rejeitos argilosos variavam entre 0,1 a 0,37. Qiu e Sego (2001) realizaram ensaios de consolidação em quatro rejeitos, cujos valores de Cc foram: Cobre 
$(0,056$ a 0,094) Ouro $(0,370$ a 0,396), Carvão Puro e Compósito de areias de óleo em rejeitos consolidados (0,271 a 0,319).

Hu et al. (2017) mencionaram em seus estudos os índices de vazios (e) e valores de $C_{c}$ dos quatros rejeitos, sendo eles: rejeitos finos ( $e=1,41$ e $C c=0,260)$ e granulares $(e=0,74$ e $C c=0,046)$ de minério de ferro de Yuhezhai; e rejeitos finos $(e=1,03$ e $\mathrm{Cc}=0,085)$ e granulares $(\mathrm{e}=0,84$ e $\mathrm{Cc}=$ $0,025)$ de minério de cobre de Bahuerachi.

Outros estudos podem ser citados como o de Morris, Lockington e Apelt (2000), que estabeleceram correlações para os parâmetros de consolidação de rejeitos de minas de carvão de New South Wales, bauxita de Western Austrália e argilas fosfatadas da Florida usando relações normalizadas entre índice de liquidez e tensão de consolidação e índice de vazios normalizados com tensão de consolidação.

Bhandhro (2014) elenca valores típicos de pesquisadores geotécnicos, de rejeitos de minérios de cobre, tanto fino quanto granular. Shamsai et al. (2007) fez um estudo de caso que citou valores de consolidação de rejeitos de minério de cobre e os trabalhos do Marcus (1997).

\section{BARRAGEM DE MINERAÇÃO OU DE CONTENÇÃO DE REJEITOS}

Do ponto de vista conceitual, as barragens, em geral, sejam de acumulação de água ou de mineração, são definidas na Lei $12334 / 2012$. A conceituação mais restrita destas estruturas se encontra na NBR 13208 (2017).

A NBR 13028 (2017) conceitua as barragens de mineração como " barragens, barramentos, diques, reservatórios, cavas exauridas com barramentos construídos, associados às atividades desenvolvidas com base em direito minerário, utilizados para fins de contenção, acumulação ou decantação de rejeito de mineração ou descarga de sedimentos provenientes de atividades em mineração, com ou sem captação de água associada, compreendendo a estrutura do barramento e suas estruturas associadas". A Figura 3 ilustra um exemplo de barragem de rejeitos mineral.

Vick (1990) afirmou que inicialmente é executado um aterro denominado dique de partida, sendo o mesmo concebido com solo de empréstimo, cuja a geometria deve ser prevista considerando uma capacidade de retenção de rejeitos para um período de lavra de dois ou três anos. Posteriormente são desenvolvidos alteamentos, que são aterros que também podem ser construídos com materiais de empréstimo, estéreis, por deposição hidráulica ou por hidrociclonagem (Ver item 4.3.2). Os alteamentos podem assumir geometrias e especificações diferentes.

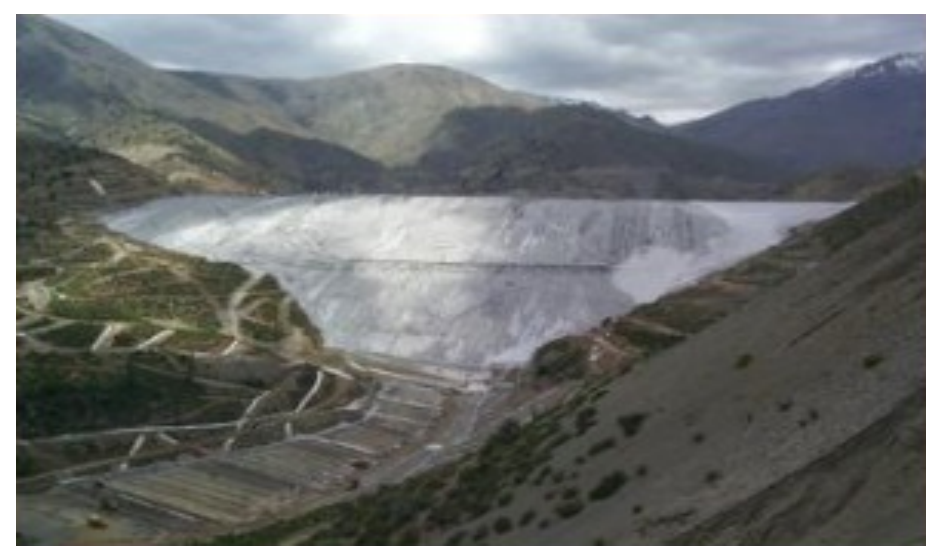

Figura 3. Barragem de rejeito de El Mauro (Fonte: TechnoMine, 2017). 
A NBR 13.028 (2017) cita que as barragens de rejeitos de mineração podem ser executadas solo, enrocamento ou até mesmo com rejeitos de mineração. Gerscovich (2012) comenta a possibilidade de se utilizar estéril no aterro compactado.

Do ponto de vista descritivo a respeito do sequenciamento construtivo, podem ser citados os trabalhos do Lucia (1981); U. S Environmental Protection (1994); Gaioto (2003); Alsharedah (2015); Soares (2010); e Portes (2013).

\subsection{Métodos construtivos das barragens de rejeitos}

Quanto aos métodos construtivos, do ponto de vista convencional existem três: a) Método de Montante; b) Método de Linha de Centro e c) Método de Jusante. Existem muitas fontes na literatura que explicam estes métodos: Lucia (1981); Vick, (1990); U. S Environmental Protection (1994); IBM (1995); Hallman e Dorey (1995); Ribeiro (2000); Mular, Halbe e Barratt (2002); Hernandez (2002); Gaioto (2003); Araújo (2006); Soares (2010); Bhanbhro (2014); Alsharedah (2016); Tanchev (2012); Lazarim (2015); Fell et al. (2015).

Muito embora a NBR 13.028 (2017) apenas faça menção as barragens com métodos construtivos mais tradicionais, existe alternativamente o Método Misto, que mescla as técnicas dos métodos convencionais, segundo Oliveira e Abrão (2015). Haile e Brouwer (1994) descrevem o Método de Linha de Centro Modificado, que mescla Método Jusante com o Montante. Como exemplo desta técnica no Brasil existe a barragem de contenção de rejeitos minerais de Santo Antônio, em Paracatu-MG. Na Figura 4 ilustra os métodos construtivos existentes de barragens de contenção de rejeitos.

Mular, Halb e Baratt (2002) afirmaram que este método permite que a linha central da crista da terra se mova levemente a montante, otimizando a quantidade de materiais de construção necessários na zona de revestimento a jusante do aterro.
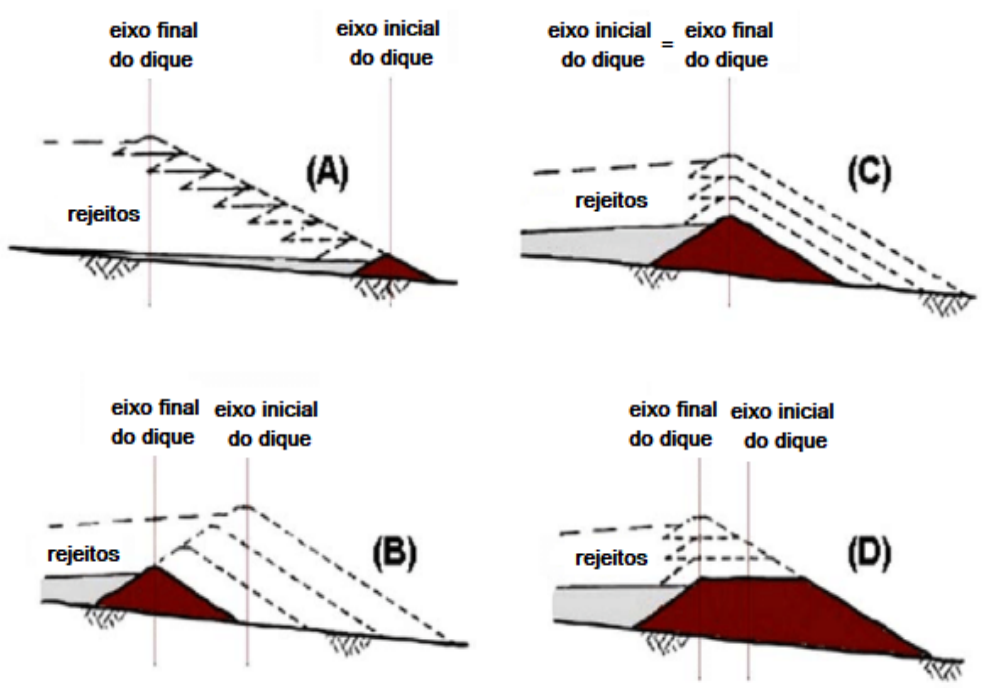

Figura 4: Tipos de barragens de mineração construídas através de enchimento hidráulico usando os próprios resíduos de mineração. A) Linha montante, B) Linha jusante, C) Linha de centro e D) Linha de centro modificada. (Fonte: Modificado de Alberruche et al., 2016)

\subsection{Comparação, desvantagens e vantagens dos métodos construtivos}


Soares (2010) enfatizou alguns aspectos referentes às vantagens e desvantagens a respeito de cada método construtivos. Quanto as vantagens:

a) Montante - Menor custo e maior velocidade no alteamento;

b) Jusante - Mais Segura;

c) Linha de Centro - Variação do volume de underflow.

Em relação aos aspectos desvantajosos:

a) Montante - Mais instável, segundo Rico et al. (2008) e ICOLD (2001);

b) Jusante - Maior custo devido ao volume de aterro do dique e deslocamentos do aterro de jusante;

c) Linha de Centro - Maior tempo e quantidade compactação comparado aos outros métodos.

Araújo (2006) concluiu através de um estudo paramétrico que uma das vantagens do alteamento pelo método de linha de centro comparado ao alteamento para pelo método de montante é a redução das tensões de tração conforme há alteamento da barragem. Em barragens alteadas pelo método de montante, as tensões de tração se mantêm porque a crista se desloca para montante.

Soares (2010) discriminou, do ponto de vista técnico, os métodos construtivos das barragens de rejeitos minerais a partir da Tabela 4.

Tabela 4: Análise comparativa entre métodos convencionais de construção de barragens de rejeitos. (Fonte: Soares, 2010)

\begin{tabular}{|c|c|c|c|}
\hline Aspectos/Tipo & Montante & Jusante & Linha de centro \\
\hline Tipo de rejeito & $\begin{array}{l}\text { Mais de } 40 \% \text { de areia. } \\
\text { Baixa densidade de polpa } \\
\text { para promover segregação }\end{array}$ & Qualquer tipo & $\begin{array}{l}\text { Areias ou lamas de } \\
\text { baixa plasticidade }\end{array}$ \\
\hline $\begin{array}{l}\text { Armazenamento de } \\
\text { água }\end{array}$ & $\begin{array}{l}\text { Não recomendado para } \\
\text { grandes volumes }\end{array}$ & Boa & $\begin{array}{c}\text { Não recomendado } \\
\text { para armazenamento } \\
\text { permanente }\end{array}$ \\
\hline Resistência sísmica & $\begin{array}{l}\text { Baixa em áreas de alta } \\
\text { sismicidade }\end{array}$ & Boa & Aceitável \\
\hline $\begin{array}{l}\text { Restrições de } \\
\text { alteamento }\end{array}$ & $\begin{array}{l}\text { Sugere-se menos de } 5 \text { a } 10 \\
\text { m/ano }\end{array}$ & --- & Pouca \\
\hline $\begin{array}{l}\text { Requisitos de } \\
\text { alteamento }\end{array}$ & Solo Natural. & $\begin{array}{l}\text { Rejeitos ou } \\
\text { estéril }\end{array}$ & Rejeitos ou estéril \\
\hline $\begin{array}{l}\text { Custo relativo do } \\
\text { aterro }\end{array}$ & Baixo $\left(V_{m}\right)$ & $\begin{array}{l}\text { Alto } \\
\left(3 \mathrm{~V}_{\mathrm{m}}\right)\end{array}$ & $\begin{array}{l}\text { Médio } \\
\left(2 \mathrm{~V}_{\mathrm{m}}\right)\end{array}$ \\
\hline
\end{tabular}

Marcus (1997) apontou uma análise comparativa entre os métodos construtivos de barragens de rejeitos. Em relação ao método de linha de centro modificada pode-se estabelecer que oferece uma alternativa de baixo custo para a construção a jusante ou centralizada em áreas de alto risco sísmico e para rejeitos com pouca ou nenhuma resistência. (HAILE E BROUWER, 1994) 
Hayle e Brower (1994) afirmaram que podem ser construídos em etapas usando equipamentos de mineração padrão e materiais sobrecarregados de operações de mineração em andamento. Após a primeira ou duas etapas iniciais, nenhuma outra construção é necessária na face a jusante, o que permite a recuperação contínua durante as operações.

\subsection{Técnicas de disposição de rejeitos}

Lozano (2006) citou que a disposição de rejeitos pode ser feita a céu aberto, subterrânea e subaquática. Porém a técnica de disposição a céu aberto é mais comum e pode ser feita em pilhas controladas ou estruturas de contenção localizadas em bacias ou vales. No geral, as técnicas de disposição podem ser subaquáticas ou subaéreas.

Fell et al. (2015) afirmaram que a escolha do método subaquático se torna interessante por motivos climáticos, falta de uma grande área de descarga, controle de geração de ácido ou outras razões. Beier (2015) citou que os rejeitos com potencial para oxidar e produzir DMA (drenagem ácida de minas) podem requerer o descarte subaquático (abaixo da água) para limitar o oxigênio disponível em contato com as extremidades sulfídricas. Lozano (2006) afirmou que o método subaquático é inviável devido aos possíveis impactos negativos no ecossistema.

Fell et al. (2015) apontaram que a escolha do método subaquático para deposição de rejeitos finos e com alto teor de argila permite que se atinga geralmente uma densidade baixa, boa resistência ao cisalhamento e tendência a maior compressibilidade.

No que tange a técnica de deposição subaérea, Knight e Haile (1983) apresentaram um dos trabalhos mais clássicos a respeito da descrição da técnica. Beier (2015), afirmou nas barragens de rejeitos, as técnicas mais usuais são:

a) Descarga de ponto único ("Single Point Discharge");

b) Descarga em pontos múltiplos ("Spigotting").

Rejeitos são geralmente transportados para a lagoa através de minerodutos ou calhas. Os mesmos são transportados em teores de água que podem se aproximar de $100 \%$ ou mais. Do ponto de vista de tipicidade, os mesmos são descarregados por um sistema de descarga periférica, onde a separação do tamanho da partícula ocorre por efeitos gravitacionais, ou eles são separados usando um hidrociclone. Em um sistema de descarga periférica, os rejeitos são depositados perto da crista da represa em consistência de lama. (LUCIA,1981)

Lighthall, Watts e Rice (1989) descrevem os métodos de deposição através de Spigotting e Cycloning e comentam sobre a construção de células. Os autores afirmaram que a construção de células é o método pelo qual os fluxos de lama são descarregados para uma célula de preenchimento hidráulico. São criados diques de decantação para permitir que os sólidos se depositem e a água excedente seja destinada à extremidade da célula oposta ao ponto da descarga.

\subsubsection{Hidromotores (Spigots) - Descarga em ponto único e em pontos múltiplos}

Quanto ao método subaéreo, Beier (2015) citou que é um método de deposição tipicamente usado em represas de armazenamento de superfície convencionais. Os rejeitos são depositados acima do nível de decantação por vários spigots de ponto único (Ver Figura 5) ou pontos múltiplos (Ver Figura 6) na praia. Partículas sólidas se soltam da lama enquanto os rejeitos escorrem pela praia e perdem energia. Após a deposição, a densidade das partículas depositadas pode aumentar devido à drenagem e evaporação (dependendo do clima). 
Vick (1990) citou que o material descarregado representa uma mistura de água e sedimentos (rejeitos) denominada polpa, cuja concentração desse material varia entre $15 \%$ e $55 \%$ de sólidos. Após o espessamento é possível a obtenção de polpas na faixa de 40 a 50\%.

McPhail e Wagner (1987) citaram que o sistema de deposição por hidromotores baseia-se na necessidade de garantir uma secagem e drenagem adequadas dos rejeitos na área à montante do dique, maximizando os efeitos da evaporação natural e da drenagem. O sistema envolve o uso de linhas de tubulações com várias saídas referidas como um tubo ramificado.

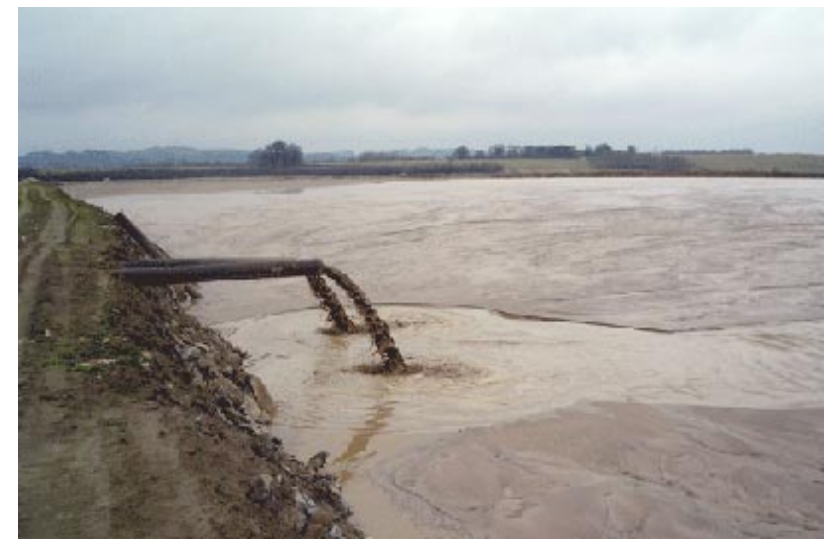

Figura 5: Spigot em ponto único. (Fonte: Tailing info, 2018a)

Australian Government Department of Industry (2016) informou que o método de pontos múltiplos comparado ao método de descarga em ponto único possibilita: a produção de uma praia mais inclinada; obtenção de maior controle sobre a direção da praia de rejeitos e, portanto, sobre a direção de água sobrenadante e escoamento superficial em direção ao decantador; deposição de elevações finas e controláveis de rejeitos e do ciclo de deposição de rejeitos para facilitar; consolidação e secagem em toda a profundidade dos rejeitos armazenados; e facilidade de captação a montante, juntamente com o potencial para usar rejeitos grossos dessecados depositados perto da parede.

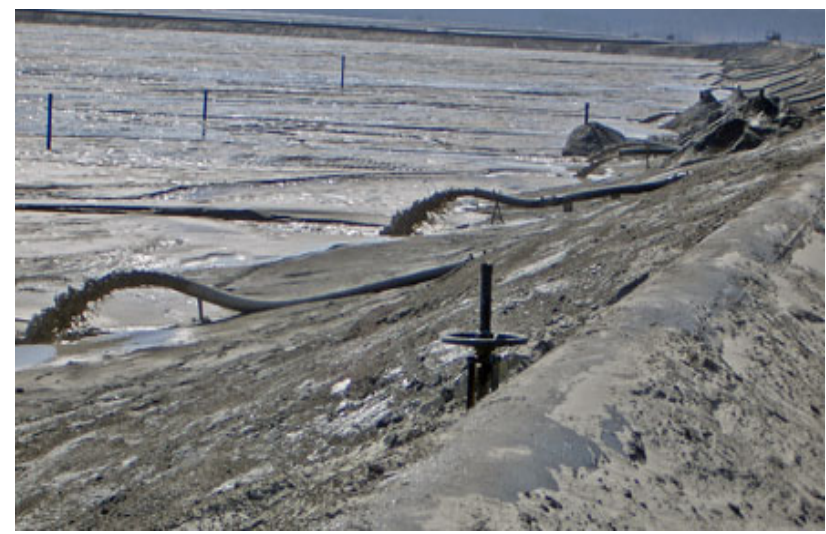

Figura 6: Spigot em pontos múltiplos. (Fonte: Tailing info, 2018b)

ICOLD (2001) exemplifica várias barragens de rejeitos pelo mundo que utilizaram este método de deposição. Essas técnicas podem ser explanadas em algumas referências literárias, como McPhail e Wagner (1987); Vick (1990); U. S. Environmental Protection Agency (1994); 
Ribeiro (2000); Gaioto (2003); Araújo (2006); D’Agostino (2008); Soares (2010); Fell et al.(2015); Lazarim (2015); e Beier (2015).

\subsubsection{Hidrociclonagem - Técnica de fracionamento de grãos}

Portes (2013) citou que os hidrociclones (Ver Figura 7) são utilizados quando o rejeito não apresenta as características geotécnicas adequadas, possuindo a função de retirar a água da polpa, promovendo a recirculação de água no processo industrial e separar as frações finas e granulares. O princípio da segregação granulométrica é a sedimentação centrífuga. (CARRISO E CORREIA, 2004)

Os mesmos afirmaram que as partículas mais grossas e mais densas são arremessadas às paredes e descarregadas na abertura inferior, o apex, constituindo o underflow. Já as partículas mais finas, menos densas e grande parte da fase líquida são dirigidas para o centro do hidrociclone e saem por um cilindro na parte superior do aparelho, denominado vortex finder, constituindo o overflow, conforme Figura 7, com esse material produzem-se As praias de rejeitos.

McPhail e Wagner (1987) afirmaram que uma vez separados, a fração grosseira ("underflow") pode ser útil para a construção de aterro de contenção de rejeitos. Devido ao menor teor de umidade e melhores características de drenagem, este material tende a ter melhor desempenho sob condições de carregamento sísmico.

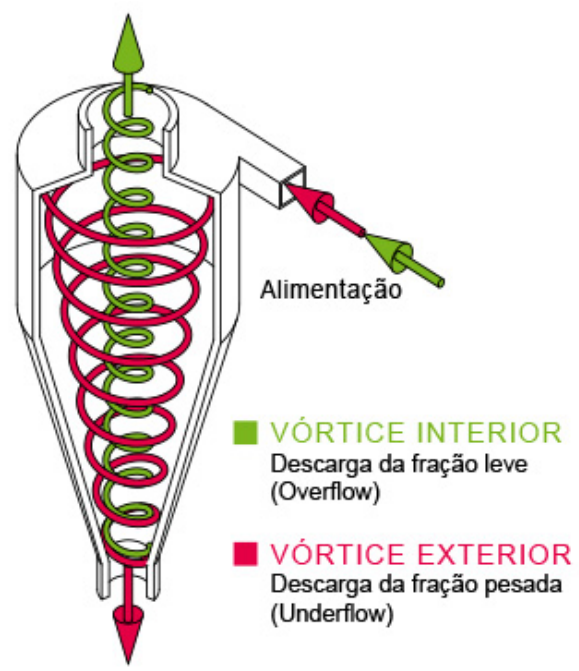

Figura 7: Detalhamento de um hidrociclone (Fonte: AKW,2018)

Alguns trabalhos como Bradley (1965); Lucia (1981); Svarovsky e Thew (1992); U. S. Environmental Protection Agency (1994); Ribeiro (2000); ICOLD (2001), Carriso e Correia (2004); Araújo (2006); Soares (2010); Alsharedah (2015); Jun, Suo e Quan (2009); Lazarim (2015); e Beier (2015) informam especificações e demais informações sobre a técnica.

\subsubsection{Sistemas de decantação}

McPhail e Wagner (1987) afirmaram que os sistemas de decantação são direcionados para decompor e remover a água sobrenadante da barragem de rejeitos.

Cambridge et al. (2018) citaram que a estrutura decantação tem como objetivo principalmente o retorno da água reciclada armazenada para a planta durante as operações. $O$ 
decantador pode incluir um sistema de gravidade com controle de bitola ou um retorno bombeado de uma barcaça flutuante (Ver Figura 8) ou de torre fixa (Ver Figura 9).

Os mesmos afirmaram que as superfícies de decantadores fixos variam conforme 0 projeto. Desde as torres centrais até as calhas laterais, são geralmente construídas em concreto e incluem um sistema para elevar o nível de retirada à medida que a altura da deposição aumenta. As torres circulares localizadas no centro do depósito têm a vantagem de permitir a deposição periférica do aterro hidráulico e reduzir o risco de eventos de inundação, e podem ser o meio mais eficiente e rentável de retornar à água, já que a infraestrutura associada é fixa e instalada durante pré-deposição.

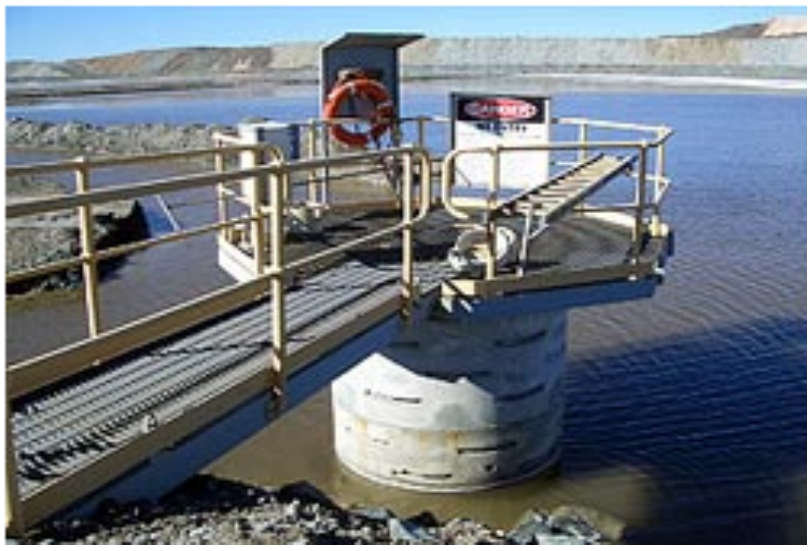

Figura 8: Sistema de decantação de rejeitos através de torres (Fonte: Tailing. Info, 2018c).

Fell et al. (2015) apontou benefícios desta técnica ao trazer à tona a flexibilidade e requerer controle menos rigoroso da deposição de rejeitos para manter a lagoa de decantação próxima à torre de decantação. Com isso, evita a fraqueza potencial, de um ponto de vista interno de erosão e tubulação, de ter um conduto através do aterro.

As barcaças podem ser fixas ou móveis e devem ser adequadas de forma suficiente para remoção das demandas diárias de decantação, bem como o acúmulo de água de chuva. A barcaça também deve estar situada em um local de fácil acesso para fins de manutenção e inspeção.

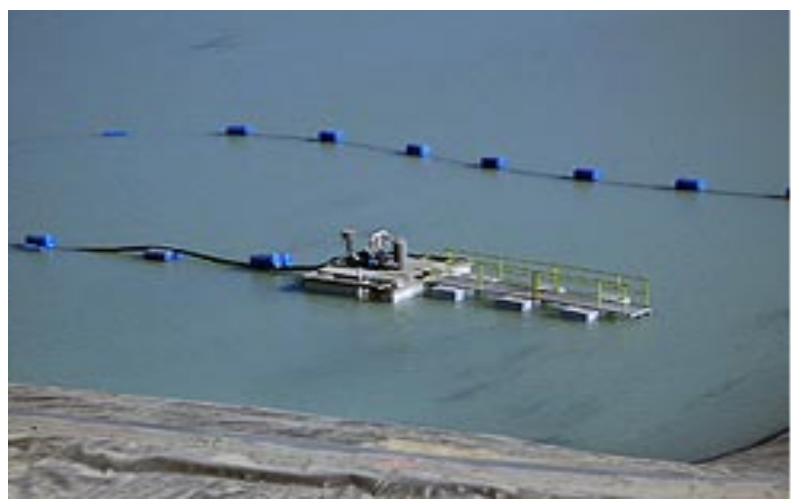

Figura 9. Sistema de decantação de rejeitos através de barcas flutuantes (Fonte: Tailing. Info, 2018c).

McPhail e Wagner (1987) afirmaram que os sistemas de barcaças flutuantes compreendem uma bomba preparada montada em uma jangada que está localizada centralmente dentro da área da piscina. Um tubo de decantação é "flutuado" através da piscina para a barcaça e suportado acima da superfície de rejeitos e colocado sobre a crista da parede. 
Deve-se atentar ao funcionamento destas estruturas na fase de operação, uma vez que as mesmas realizam o controle da matéria sobrenadante, consequentemente a danificação pode resultar em transbordamento, altas taxas de fluxo e aumento de poropressão, a ponto de instabilizar a estrutura da barragem. O exemplo clássico é a barragem de Stava, na Itália, em 1985.

\subsubsection{Formação da praia de rejeitos}

Uma vez descartada a lama há uma tendência de deposição dos grãos ou de fluxo próximo a superfície do aterro em diferentes regimes, gerando assim arraste de fundo. 0 processo de deposição e transporte produz uma interação entre o fluxo de sedimentos e o material presente na camada, gerando um processo erosivo ou acúmulo de material depositado. (RIBEIRO,2000)

D’Agostino (2008) afirmou que a geometria da praia de rejeitos é similar a de um perfil côncavo, sendo mais inclinado próximo ao ponto de descarga e tornando-se suave na parte final da praia.

Melentiev, Kopalshnikov e Vonin (1973) propuseram um trabalho clássico da equação do perfil de enchimento hidráulico e que foi usada extensivamente para modelar os perfis de ambos os reservatórios hidráulicos e praias de rejeitos de minas através da equação (3):

$\mathrm{h}=\mathrm{H}\left(1-\frac{x}{L}\right)^{\mathrm{n}}$

Onde:

$\mathrm{H}$ : Altura do ponto de lançamento da hidromisturas;

h: Altura de um ponto qualquer do perfil;

$\mathrm{x}$ : distância entre o ponto de lançamento da hidromistura e um ponto qualquer;

L: distância entre o ponto de lançamento da hidromistura e o início da lagoa de decantação.

$\mathrm{n}$ : expoente adimensional de concavidade da praia.

Blight e Bentel (1983) realizaram um levantamento dos perfis de praia medidos em seis barragens de rejeitos de platina. Com isso realizaram equacionaram um perfil normalizado aproximado pela equação (4):

$\frac{h}{y}=\frac{y}{x}\left(1-\frac{H}{x}\right)^{n}$

Onde:

H: distância do ponto de lançamento da hidromistura até qualquer ponto do perfil;

h: Altura de um ponto qualquer do perfil;

x: distância entre o ponto de lançamento da hidromistura e o início da lagoa de decantação;

y: Altura do ponto de lançamento da hidromistura;

$\mathrm{n}$ : expoente adimensional de concavidade da praia.

Blight e Bentel (1983) ilustraram a relação $\frac{y}{h}$ versus $\frac{x}{h}$ baseando-se na Figura 10 , onde há 
representação do gradiente médio ao longo da praia. Foram comparados os perfis de praia sem dimensões para quatro tipos diferentes de rejeitos.

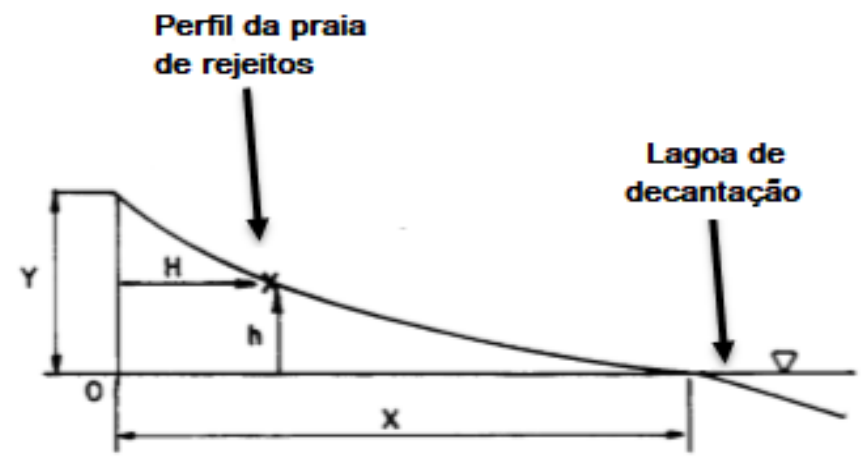

Figura 10: Perfil típico de lagoa de talude de deposição (Fonte: adaptado de Blight e Bentel, 1983).

Os perfis de rejeitos de platina, diamante e ouro foram medidos em praias de preenchimento hidráulico, sendo apenas os rejeitos de cobre representados com perfil médio de uma série de cones de fluxo inferior do ciclone. Dada a variabilidade das propriedades dos rejeitos, cada material tem valor $\mathrm{n}$ característico, conforme Figura 11.

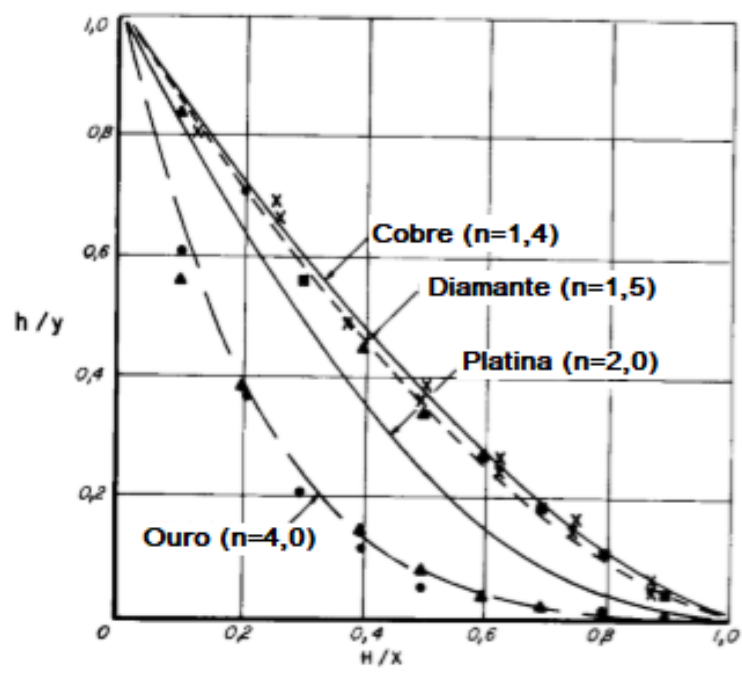

Figura 11: Dimensionamento dos perfis de rejeitos a partir dos tipos de minérios (Fonte: Blight e Bentel, 1983).

Parker et al. (1998) desenvolveram uma equação para descrever fluxos tanto em leques aluviais naturais quanto em praias de rejeitos de minas. Neste modelo, presume-se que as reservas de rejeitos são gerenciadas de tal forma que a aglomeração de equilíbrio, em que a elevação do leito em toda a praia ocorre a uma taxa média constante ao longo do tempo, é atingida. Também se assume que as entradas de água e sedimentos são efetivamente constantes; que o fluxo é canalizado e se espalha lateralmente à medida que passa pela praia; e que todo o sedimento de entrada é retido na praia.

Morris (2004) desenvolveu uma formulação a partir da combinação de Morris (1993) e Parker et al. (1998), cuja largura do canal varia linearmente ao longo de L. Isso leva à conclusão de que a descarga de sedimentos de carga de leito varia parabolicamente em $L$ e atinge zero em $x$ $=\mathrm{L}$, conforme equação (5): 
$S=S_{0} \exp \left(-K x^{2}\right)$

Onde:

S: Inclinação de fundo;

$\mathrm{S}_{\mathrm{o}}$ : Inclinação do ponto $\mathrm{x}=0$;

$\mathrm{K}$ : coeficiente de concavidade da praia;

x: distância entre o ponto de lançamento da hidromistura e o início da lagoa de decantação.

O mesmo afirmou que o coeficiente $k$, que varia de praia para praia, pode ser expresso na forma adimensional pela equação (6):

$\mu=k x^{2}$

Onde:

k: coeficiente de concavidade da praia;

$\mathrm{x}$ : distância entre o ponto de lançamento da hidromistura e o início da lagoa de decantação.

Obs: Valores de k e $\mu$ entre zero e infinito implicam perfis de praia côncavos e valores de zero implicam uma inclinação constante.

Fitton, Bhattacharya e Chryss (2008) estudaram modelos de formato de praia a partir modelagem geométrica tridimensional (3D) da superfície da praia de uma pilha de rejeitos formada através da descarga variável de uma pasta não segregante que periodicamente muda em sua composição, cuja vazão total de saída foi definida como uma sequência de períodos finitos menores de descarga uniforme.

Os estudos de Morris (2004) e Fitton, Bhattacharya e Chryss (2008) elencam e descrevem mais métodos.

\subsubsection{Segregação granulométrica em aterros hidráulicos}

Santos e Meyer (1980) realizaram um estudo baseado no trabalho de Melentiev, Kopalshnikov e Vonin (1973) em relação ao método segregação granulométrica em aterros hidráulicos. Sabe-se que os aterros hidráulicos são gerados através do lançamento de uma mistura de água com partículas sólidas e que escoa para locais mais baixos, onde o excesso de água é drenado e conduzido para fora da área do aterro.

As partículas sólidas mais graúdas depositam-se nas proximidades do local de lançamento, enquanto que os materiais mais finos são arrastados e depositados a uma certa distância. Com isso, a propriedades físicas do solo se alteram (permeabilidade e resistência ao cisalhamento). D' Agostino (2008) explicou que os aterros hidráulicos formam perfis côncavos compatíveis com os parâmetros de fluxo do meio. A segregação das partículas que ocorre na praia permite que haja a redução de inclinação, sendo que a região próxima ao ponto de descarga predomina a deposição das partículas mais grossas e conforme há o afastamento do ponto de descarga, ocorre uma suavização do perfil, sendo ampla a concentração de finos.

O método de Melentiev permite o entendimento da distribuição granulométrica ao longo da praia de sedimentação do aterro hidráulico. A partir da granulometria dos grãos, vazão do 
sólido com o fluído, tipo de equipamento, distância de lançamento, e outros pode-se entender o comportamento da segregação do material. Para aplicação do estudo, se utilizam três parâmetros adimensionais anunciados nas equações (7), (8) e (9):

a) Parâmetro de fluxo de água - E;

$\mathrm{E}=\frac{d}{h . i}$

Onde:

d: diâmetro médio do solo na fração considerada;

$\mathrm{h}$ : profundidade do fluxo de água;

i: declividade da superfície do aterro.

b) Parâmetro de fracionamento hidráulico - $\rho_{\circ}$;

$$
\rho_{o}=\frac{\varphi_{i}}{\varphi_{o}}
$$

Onde:

$\varphi_{i}$ : porcentagem em peso de determinada fração no aterro hidráulico;

$\varphi_{o}$ : porcentagem em peso de determinada fração no empréstimo.

c) Parâmetro da distância $-X_{0}$;

$$
\mathrm{xo}_{\mathrm{o}}=\frac{X}{L}
$$

Onde:

$\mathrm{x}$ : distância do ponto de lançamento da hidromistura até o ponto onde se pretende determinar a granulometria média do solo na fração considerada;

L: comprimento total da "praia " de deposição.

D' Agostino (2008) afirmou que o processo de segregação hidráulica é variável em função das condições de fluxo, tipo de fluído, concentrações e características dos sedimentos, granulometria e presença de aditivos químicos no fluído.

Soares (2010) e Portes (2013) afirmaram que a segregação hidráulica seleciona as partículas de acordo com seu peso, próximo ao ponto de descarga e para tanto formam-se três zonas (ver Figura 12) distintas: a) zona de alta permeabilidade (material granular); b) zona de permeabilidade intermediária, que é formada entre as zonas de alta e baixa permeabilidade; c) zona de baixa permeabilidade e distante do ponto de descarga constituída por material fino. Esta afirmação é válida para uma massa específica dos grãos constante. 


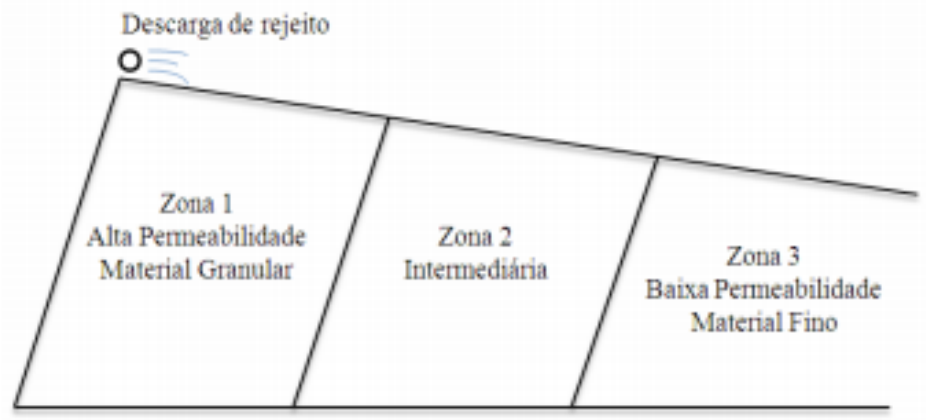

Figura 12: Separação de zonas com diferentes permeabilidades no aterro de rejeitos (Fonte: Adaptado de Vick (1990 apud Portes, 2013).

Os estudos de Melentiev, Kopalshnikov e Vonin (1973); Vick (1990); Ribeiro (2000); Araújo (2006); D’Agostino (2008); e Portes (2013) elencam e descrevem mais métodos.

\subsection{Critérios de estabilidade das barragens de rejeitos minerais}

A NBR 13028 (2017) informa que em termos de estabilidade, as análises devem ser feitas por etapas e globalmente considerando o dique de partida e a sua fundação, os maciços de alteamento independentemente do método construtivo, sua fundação e o rejeito, tendo como objetivo obter as superfícies potencias de ruptura local e global.

A mesma norma recomenda a obtenção de valores mínimos de fator de segurança a partir de análises determinísticas de estabilidade em condições de carregamento drenados (tensões efetivas) e não drenados (tensões totais) de cada material envolvido. Salientando que no caso da avaliação a partir de condições drenadas devem ser usando parâmetros efetivos de resistência ao cisalhamento e poropressões estimadas por redes de percolação. Abaixo anuncia a Tabela 5 informando os fatores de segurança para cada situação ou fase da barragem.

Tabela 5: Fatores de segurança mínimos para barragens de mineração (Fonte: NBR 13028, 2017).

\begin{tabular}{cccc}
\hline Fase & $\begin{array}{c}\text { Tipo de } \\
\text { ruptura }\end{array}$ & Talude & $\begin{array}{c}\text { Fator de } \\
\text { segurança }\end{array}$ \\
\hline Final de construção * & $\begin{array}{c}\text { Maciço e } \\
\text { fundações }\end{array}$ & $\begin{array}{c}\text { Montante } \\
\text { Jusante }\end{array}$ & 1,3 \\
\hline $\begin{array}{c}\text { Operação com rede de fluxo em } \\
\text { condição normal de operação, nível } \\
\text { máximo do reservatório }\end{array}$ & $\begin{array}{c}\text { Maciço e } \\
\text { fundações }\end{array}$ & Jusante & 1,5 \\
\hline $\begin{array}{c}\text { Operação com rede de fluxo em } \\
\text { condição extrema de operação, nível } \\
\text { máximo do reservatório }\end{array}$ & $\begin{array}{c}\text { Maciço e } \\
\text { fundações }\end{array}$ & Jusante & 1,3 \\
\hline $\begin{array}{c}\text { Operação com rebaixamento rápido } \\
\text { do nível d'água do reservatório }\end{array}$ & Maciço & Montante & 1,1 \\
\hline $\begin{array}{c}\text { Operação com rede de fluxo em } \\
\text { condição normal }\end{array}$ & Maciço & Jusante & 1,5 \\
\cline { 3 - 4 } bntre & 1,3 \\
\hline $\begin{array}{c}\text { Solicitação sísmica, com nível máximo } \\
\text { do reservatório }\end{array}$ & $\begin{array}{c}\text { Maciço e } \\
\text { fundações }\end{array}$ & $\begin{array}{c}\text { Montante } \\
\text { e Jusante }\end{array}$ & 1,1 \\
\hline
\end{tabular}


* Etapas sucessivas de barragens alteadas com rejeitos não podem ser analisadas como final de construção, devendo atender aos fatores de segurança mínimos estabelecidos para as condições de operações.

Gaioto (2003) anunciou recomendações detalhadas de fatores de segurança aplicados a barragens de terra e enrocamento abordando condições estáticas e dinâmicas de projeto, como também a situação dos taludes e tipos de ensaios para obtenção de envoltória de resistência (drenado ou não drenado) pela U.S Army Corps Of Engineers. Os valores variavam, em extremos, de 1,0 (Rebaixamento a partir do Nível de água máximo) até 1,5 na fase de operação. Tais recomendações são plenamente adequáveis a barragens de contenção de rejeitos.

MIN (2002) fez recomendações de fatores de segurança para estabilidade de taludes de barragens de acúmulo de água e rejeitos observados apenas em condições estáticas (Percolação permanente com reservatório na cota máxima normal, esvaziamento rápido, término da construção antes do enchimento do reservatório), variando entre 1,25 a 1,5.

\subsection{Causas de rupturas de barragens de rejeitos}

Rico et al. (2008) identificaram quinze causas de falhas diferentes de rupturas de barragens de rejeitos. Em muitos casos (39\%), as rupturas nas barragens resultaram de uma combinação de diferentes fatores, por exemplo, ocorrência de falhas devido a fatores meteorológicos (chuvas intensas, furacões, derretimento de gelo, acumulação de gelo na barragem de rejeitos, etc), associação com overtopping, infiltração, falha de fundação ou má gestão das estruturas. A maior parte dos incidentes são referentes a fatores meteorológicos como, por exemplo, períodos de chuva incomuns e neve, representando $25 \%$ dos casos mundiais e $35 \%$ na Europa.

Azam e Li (2010) apontaram os fatores climáticos e o mal gerenciamento como principais fatores inerentes às falhas das barragens. As falhas causadas pelas chuvas incomuns aumentaram de $25 \%$ (antes do ano 2000) a 40\% (após 2000). Isso pode ser atribuído às mudanças recentes nas condições climáticas, particularmente nas minas próximas aos mares e/ou localizadas em regiões equatoriais que receberam altas precipitações. As falhas ocasionadas devido à má gestão aumentaram de $10 \%$ a $30 \%$ para os mesmos períodos. Este aumento nos índices de falhas pode ser atribuído à grande exploração de recursos sendo depositados nos reservatórios sem o devido monitoramento e controle.

ICOLD (2001) anunciou um levantamento de causas de rupturas a partir de um banco de dados de 221 barragens pelo mundo e concluíram que as três maiores causas de incidentes de barragem de rejeitos são devido à instabilidade de talude, galgamento ("Overtopping") e terremotos. A maioria dos incidentes ocorre em barragens ativas e, expressivamente, em barragens que adotam o método construtivo de montante.

Wei et al. (2016) apresentar casos históricos de barragens na china entre os anos de 1962 e 2008 que apontam a predominância de rupturas de barragens que adotam método construtivo de linha montante.

A NBR 13.028 (2017) pede uma atenção especial às barragens de linha de montante nas fases de projeto, construção, operação e desativação nestas estruturas, muito embora em anos anteriores, a NBR 13.028(1993), especificamente no item 4.2, recomendasse que se não optasse por este tipo de estrutura de contenção de rejeitos.

\subsection{Casos históricos de rupturas de barragens de rejeitos (Tailings' Dam Break)}


Quando rompidas, as barragens de rejeitos possibilitam a transferência de milhões de metros cúbicos de material do reservatório para o trecho jusante, como ocorreu em: Cerro Negro (CHI) em 1965; Buffalo Creek (EUA) em 1972; Cooper (EUA) em 1973; Merriespruit (RSA) em 1994; Cataguases (BRA) em 2003; Mount Polley (CAN) em 2014; Fundão (BRA) em 2015 dentre outras ocorrências.

Davies (2002) citou que assumindo um inventário mundial de 3500 barragens de rejeitos conhecidas, nos últimos 30 anos (1970 a 2001) ocorreram 2 a 5 falhas por ano, o que é equivalente a uma probabilidade anual em algum lugar entre $1 \mathrm{em} 700$ a $1 \mathrm{em} \mathrm{1750.} \mathrm{Esta} \mathrm{taxa} \mathrm{de}$ falha não oferece uma comparação favorável com menos de 1 em 10.000 que parece representar represas convencionais.

Após o evento de ruptura, formam-se relevos variados no reservatório destas barragens dependendo do mecanismo de falha (liquefação, galgamento, piping, etc), tipo de rejeito (ferro, ouro, magnésio, cobre, etc.), geometria (altura, largura e comprimento), condições de saturação (grau de saturação), condições de adensamento (grau de adensamento) e outros. Entretanto, em rupturas estáticas (liquefação estática) é comum a formação de cunhas no entorno da brecha, as quais limitam o material transferido em relação ao material estável.

Existem determinadas referências que tratam de casos históricos de barragens de rejeitos que romperam, como é o caso Lucia (1981); Jeyapalan, Ducan e Seed (1983); Espósito (2000); ICOLD (2001), Davies (2002); Rico et al. (2008); Ávila (2012) e Kossof et al.(2014).

\section{LEGISLAÇÃO E NORMAS BRASILEIRAS}

Do ponto de vista ambiental, O art. 20 do CONAMA (1997) informa que "a localização, construção, instalação, ampliação, modificação e operação de empreendimentos e atividades utilizadoras de recursos ambientais consideradas efetiva ou potencialmente poluidoras, bem como os empreendimentos capazes, sob qualquer forma, de causar degradação ambiental, dependerão de prévio licenciamento do órgão ambiental competente, sem prejuízo de outras licenças legalmente exigíveis".

Desta forma, a licença ambiental para empreendimentos e atividades consideradas efetiva ou potencialmente causadoras de significativa degradação do meio, como é caso das barragens de mineração, dependerá de prévio estudo de impacto ambiental e respectivo relatório de impacto sobre o meio ambiente (EIA/RIMA), ao qual dar-se-á publicidade, garantida a realização de audiências públicas.

No ano de 2010, foi publicada a Lei 12.334 que estabelece a Política Nacional de Segurança de Barragens (PNSB) e cria o Sistema Nacional de Informações sobre Segurança de Barragens (SNISB), sendo a mesma destinada a barragens de acumulação de água para quaisquer usos, à disposição final ou temporária de rejeitos e à acumulação de resíduos industriais dependendo da geometria da barragem, capacidade do reservatório, condições químicas do rejeito e dano potencial associado. Aguiar (2014) descreve cronologicamente os trâmites políticos, encontros e formulação da Lei 12.334/2010.

Visando estabelecer critérios gerais de classificação de barragens por categoria de risco, dano potencial associado e pelo volume do reservatório, em atendimento ao art. 70 da Lei 12.334/2010, foi desenvolvida a Resolução CNRH 143/2012.

Segundo CNRH (2012), do ponto de vista de categoria de risco são consideradas os 
aspectos referentes as características técnicas, estado de conservação da barragem e plano de segurança de barragens. Em relação ao dano potencial associado (DPA) pode-se afirmar que representa uma avaliação que relaciona entre o volume de rejeitos no reservatório e os impactos sociais, ambientais e econômico. Por fim, o Plano de segurança de barragens avalia a situação do projeto (básico, executivo ou conceitual) em função estrutura organizacional e qualificação do corpo técnico, existência manuais e procedimentos para inspeções de segurança e monitoramento, Plano de ação emergencial (PAE) e relatório de inspeção e monitoramento da instrumentação e de análise de segurança.

Tendo em vista que compete ao Departamento Nacional de Produção Mineral (DNPM,) no âmbito de suas atribuições, fiscalizar as atividades de pesquisa e lavra para o aproveitamento mineral e as estruturas decorrentes destas atividades, foi desenvolvida pela Portaria DNPM 70389/2017.

A Portaria DNPM $(70.389,2017)$ representa uma exigência do Governo federal na criação do cadastro nacional de barragens de mineração, o sistema Integrado de gestão em segurança de barragens de mineração e estabelece a periodicidade de execução ou atualização, a qualificação dos responsáveis técnicos, o conteúdo mínimo e o nível de detalhamento do Plano de Segurança da Barragem, das inspeções de segurança regular e especial, da revisão periódica de segurança de barragem e do plano de ação de emergência para barragens de mineração. (Lei n. 12.334, 2010)

Em termos de normas para barragens de rejeitos, a que se encontra em vigência é a NBR 13.028 (2017). Esta norma apresenta requisitos mínimos para elaboração e apresentação de projetos de barragens de mineração, incluindo as barragens para disposição de rejeitos de beneficiamento, contenção de sedimentos gerados por erosão e acúmulo de água em mineração, visando atender às condições de segurança, operacionalidade, economicidade e desativação, minimizando os impactos ao meio ambiente. Comparada a última atualização, que ocorreu em 2006, foram valorizadas recomendações referentes ao fator de segurança em relação aos critérios de projeto, inseriu mais estudos (tecnológicos, químicos, sísmicos), trouxe à tona as análises de riscos para estruturas com dano potencial associado elevados, planos de ações emergenciais, etc.

\section{INSTRUMENTAÇÃO DE BARRAGENS DE REJEITOS}

Gaioto (2003) afirmou que a instrumentação é aplicada para fornecer informações importantes sobre o comportamento das fundações e do corpo da barragem, sendo a mesma fundamentalmente útil na fase de construção e operação.

Lindquist e Cruz (1996) descreveram a importância da instrumentação através de três aspectos:

a) Hipóteses, critérios e parâmetros adotados em projeto para fins de aprimoramento, garantia técnica e economicidade;

b) Adequação dos métodos construtivos;

c) Condições de segurança da obra para fins de medidas corretivas em tempo hábil;

Gaioto (2003) descreveu em seu trabalho um exemplo de uso de instrumentação da barragem do Morro do Ouro em Paracatu-MG, onde foram introduzidos piezômetros do tipo “ Stand pipe", piezômetros elétricos de corda vibrante, placas de recalque, marcos de deslocamentos superficial e medidores de vazão.

Há várias referências literárias e pesquisadores que anunciam, discriminam e explicam 
sobre os instrumentos comumente utilizados em barragens no geral, como é o caso do Dunniclif (1988), Lindquist e Cruz (1996), Gaioto (2003) e Silveira (2006).

\section{MODELAGENS NUMÉRICAS APLICADAS A BARRAGENS DE REJEITOS}

Neste tópico será apresentada a importância da modelagem numérica em ferramentas computacionais nas barragens de rejeitos, assim como exemplos.

\subsection{Análise de estabilidade de barragens de rejeitos}

$\mathrm{Na}$ concepção preliminar do projeto, de barragens de rejeitos, são escolhidas seções representativas para verificar se os coeficientes de segurança quanto a escorregamento de taludes estão sendo atendidos, conforme critérios de projeto. (GAIOTO, 2003)

Desta forma, muitos projetistas se subsidiam de softwares comerciais para verificação, a partir do método do Equilíbrio Limite, baseados nos métodos bidimensionais de: Bishop simplificado, Janbu, Spencer, Morgnstern \& Price e outros. Abaixo, a Figura 13, ilustra uma avaliação de estabilidade de talude do trecho jusante de uma barragem de rejeitos usando o método Spencer.

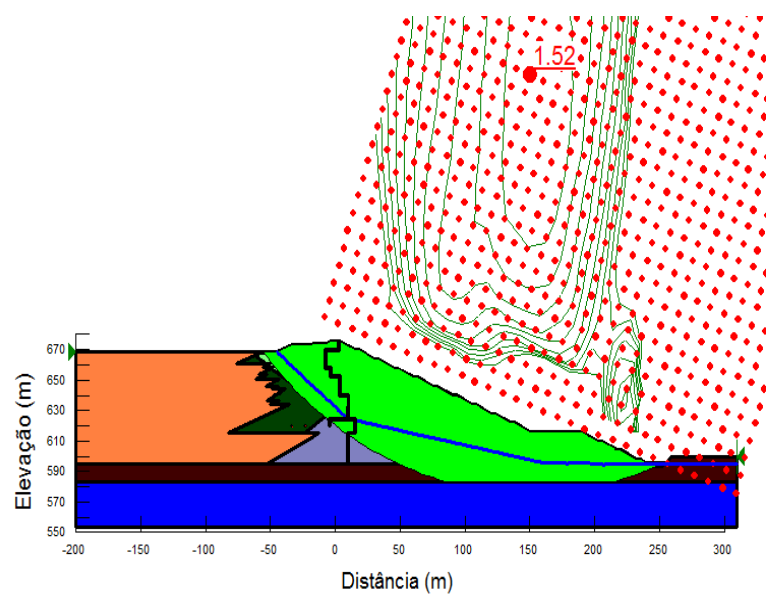

Figura 13: Análise de estabilidade de taludes de uma seção representativa de uma barragem de rejeitos. (Fonte: Autor, 2018).

\subsection{Modelos numéricos de tensão versus deformação}

Atualmente, os projetistas geotécnicos, de uma maneira geral, avaliam o comportamento de uma estrutura de barragem de rejeitos, através dos Método dos Elementos Finitos (MEF) em 2D e 3D. Desta forma, podem ser previstos com um certo nível de previsão os recalques, deformações, trincas, rupturas do maciço e demais outras anomalias. Em casos de inspeções, comportamentos não previstos podem ser entendidos e interpretados a partir de retro análise usando parâmetros calibrados de campo.

A Figura 14 e a Figura 15 exemplificam o uso de modelos numéricos bidimensionais em avaliações de tensões e deformações em barragens de rejeitos, respectivamente. No exemplo específico foram empregados parâmetros elásticos calibrados em conjunto a análises bidimensionais de tensão versus deformação para serem conduzidos a resultados compatíveis com as leituras disponíveis da instrumentação da barragem. 
Na Figura 14 ilustra uma análise de tensões no corpo da barragem, a partir de MEF, e foi percebido uma determinada concentração de tensões na região do filtro. As tensões normais na parte inferior dos tramos do filtro vertical atingem níveis bem superiores ao atingido pelo solo circundante, na mesma cota.

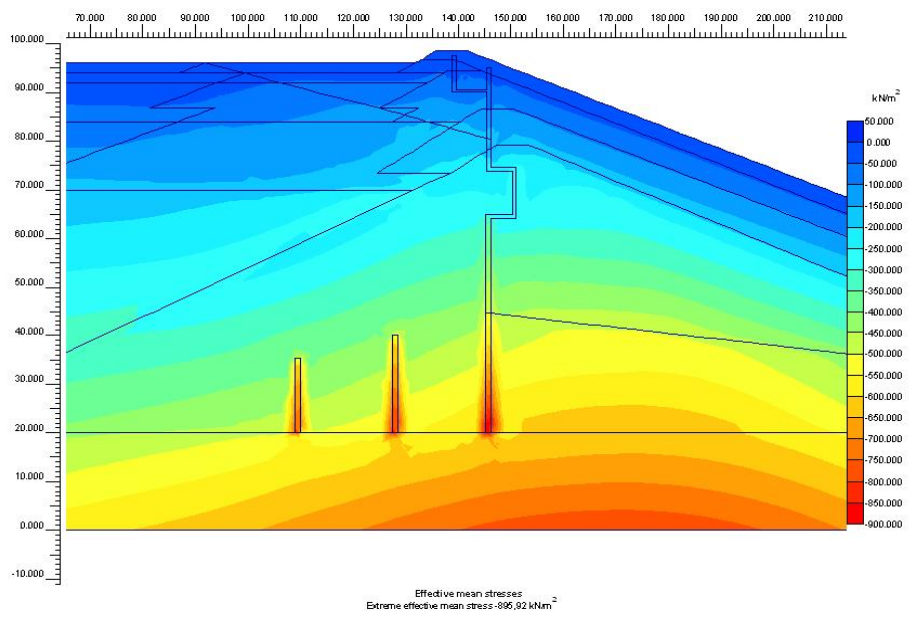

Figura 14: Concentração de tensões no filtro vertical da barragem de rejeitos (Fonte: Autor, 2018).

A Figura 15 ilustra os deslocamentos no aterro compactado a jusante, sendo especificamente mais pronunciado próximo à superfície do talude. Os deslocamentos no aterro lançado e no rejeito sob o aterro lançado direcionaram-se para sentido montante das estruturas. Em resumo, pode-se dizer que, a montante do filtro vertical, os deslocamentos horizontais são para montante, e a jusante do filtro, os deslocamentos ocorreram sentido jusante.

Usando análises tridimensionais de tensão versus deformação (Ver Figura 16) torna possível a verificação comportamental da barragem ao longo do seu comprimento. Desta forma, é possível constatar movimentos de rotação, concentração de tensões em pontos específicos, fissurações e trincas oriundos de deslocamentos específicos e demais anomalias.

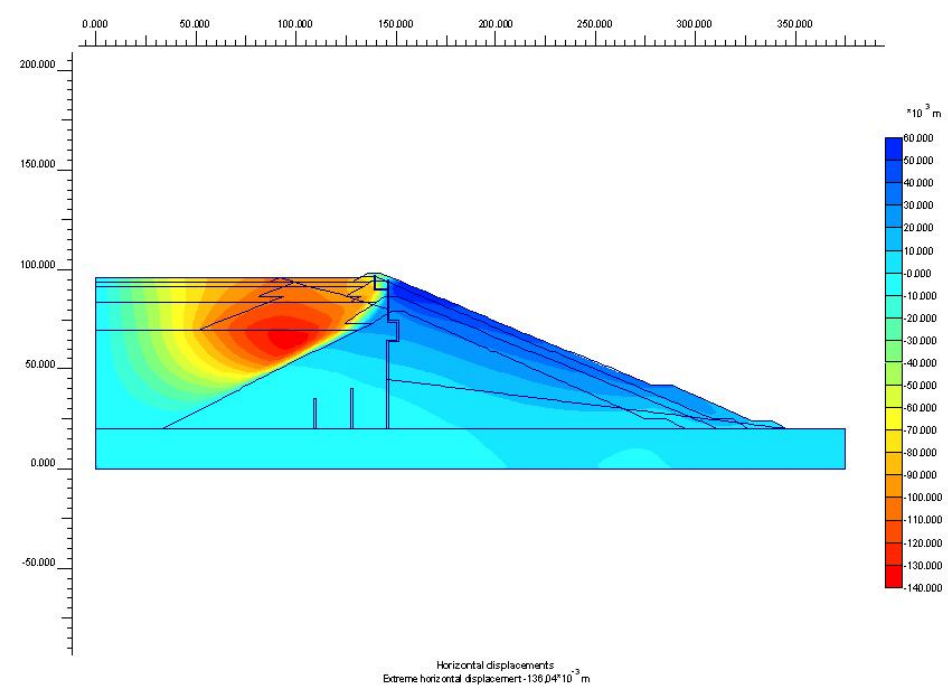

Figura 15: Deslocamentos horizontais no maciço da barragem devidos a construção de uma etapa e enchimento do reservatório. (Fonte: Autor, 2018). 


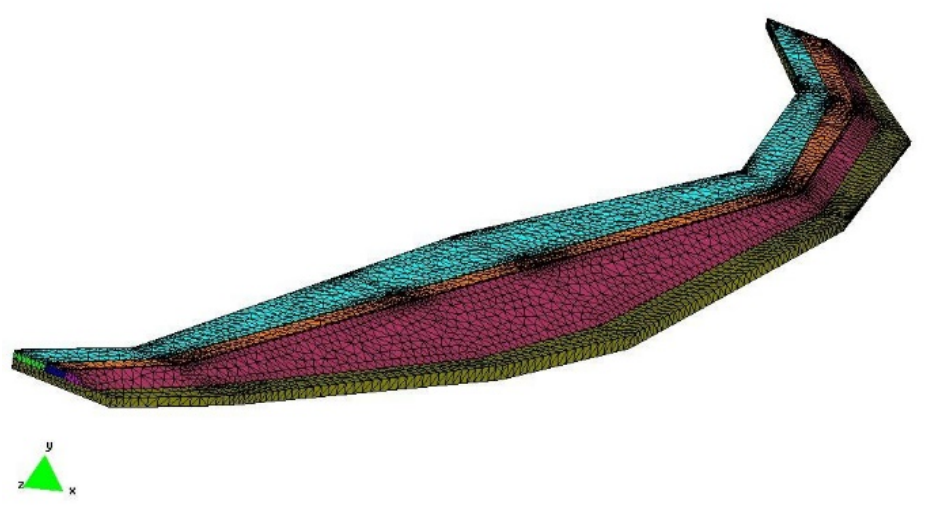

Figura 16: Aplicação do Método dos elementos finitos na superfície do modelo de barragem de rejeitos (Fonte: Autor, 2018).

A Figura 17 ilustra os deslocamentos verticais da barragem de rejeitos, onde pode ser visto que são mais pronunciados no rejeito e no aterro lançado, especificamente nas seções localizadas no centro do vale, muito embora ocorram de forma menos pronunciada em toda a extensão da barragem.

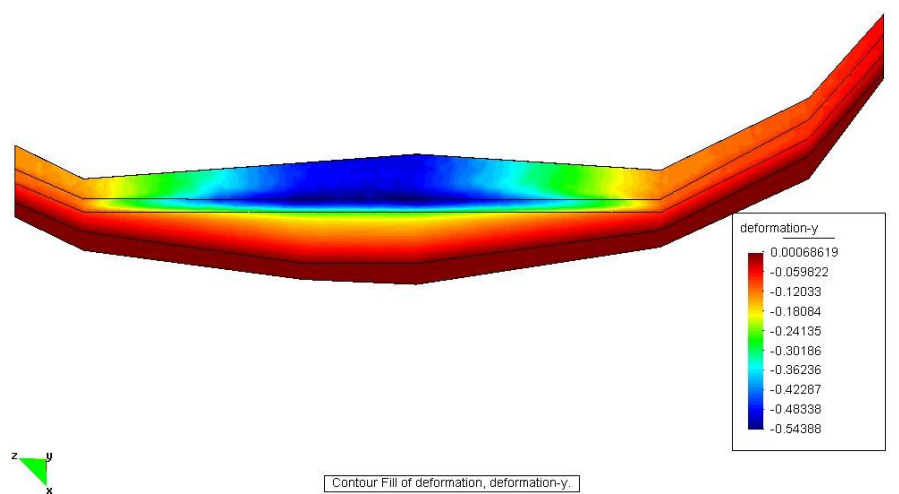

Figura 17: Deslocamentos verticais na superfície do solo (Fonte: Autor, 2018).

Como pode ser observado, os maiores valores foram observados no talude do aterro lançado e diminuem à medida que se aproximam da crista da barragem, o que indica a rotação do aterro lançado. Os deslocamentos também diminuem à medida que se aproximam das ombreiras.

Existem alguns trabalhos de modelagem numéricas na literatura referentes a consolidação, deformação, estabilidades de taludes e outros, que podem ser citados, sendo eles: Consoli (1991); Saad e Mitri (2011); Jiabin et al. (2013); Ormann et al. (2013); Bing (2014); Hassellund et al. (2016); Alsharedah (2015); Zardari et al. (2017) e Yaya, Tikou e Lizhen (2017).

\subsection{Modelos de rupturas de barragens de rejeitos}

Para se estabelecer uma avaliação quantitativa da magnitude do dano potencial de um evento de ruptura simulado, recorre-se a estimativas conservativas de previsão de material transferido de natureza empírica para geração de mapeamento de ruptura hipotética denominado estudo de Dam Break (Ver Figura 18). O estudo de ruptura de barragens representa 
um instrumento para planejamento de ações emergenciais (PAE) e análises de risco (AR) em situações críticas.

Atualmente, as modelagens de rupturas de barragens de rejeitos são geradas através da transferência de material rompido visto como fluido newtoniano. Para tanto, são utilizados modelos hidrodinâmicos a partir das equações de Saint-Venant, Navier-Stokes e outros. Alguns modelos que podem ser citados são DMBRK (1D), HEC-RAS (1D e 2D), MIKE 21 (2D), HYDRO (1D, 2D e 3D), MIKE 3(3D), FLUENT (3D) e demais outros. Tschiedel (2017) elencou os parâmetros influentes, equações e modelos hidrodinâmicos existentes.

Porém sabe-se que nas situações onde os parâmetros e modelos reológicos são inadequados podem retardar de maneira significativa o tempo de chegada da onda, consequentemente prejudicando o planejamento de ações emergenciais. Além disso, pode haver uma interrupção do escoamento de forma prematura e irreal (diminuição do alcance da onda). Por fim, a simplificação do modelo (escoamento não-newtoniano como newtoniano) pode trazer erros e incertezas menores do que os associados a parâmetros reológicos inadequados e modelos computacionais pouco empregados no meio técnico e acadêmico.

Rico, Benito e Diez-Herrero (2008) afirmaram que há uma grande variedade de parâmetros que afetam o fluxo de rejeitos da mina, incluindo a carga de sedimentos, o comportamento do fluido (Newtonian ou Bingham-plastic) que depende do tipo de falha (por exemplo, ação sísmica, liquefação estática, lâmina, etc.), reologia (que depende das partículas em suspensão), topografia, gradiente dos vales, presença de obstáculos que impedem a lama de fluir entre outros. Em termos de espalhamento de rejeitos, do ponto de vista acadêmico, podem ser citados os seguintes trabalhos:

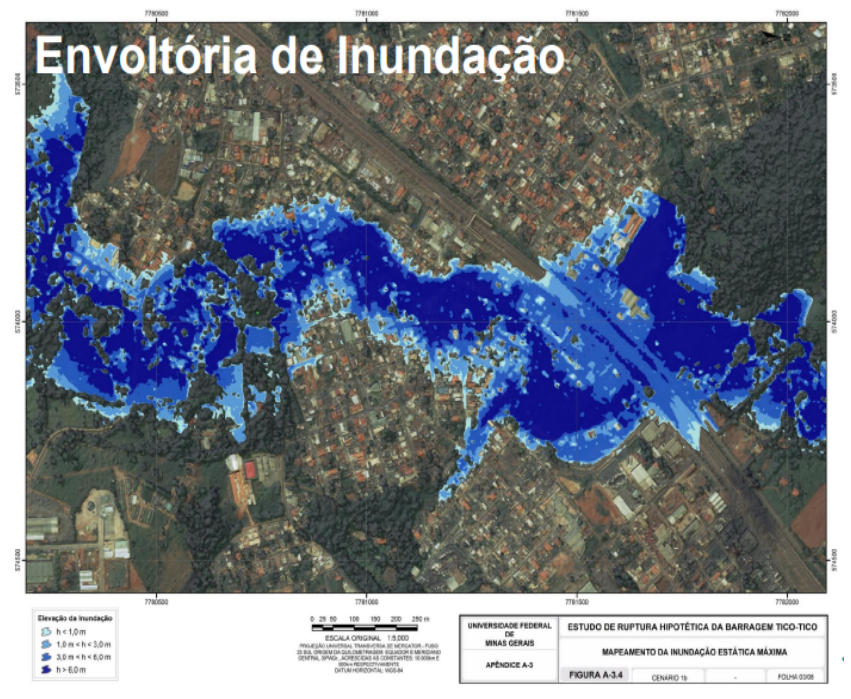

Figura 18: Avaliação de ruptura hipotética (Estudo de Dam Break) da Barragem Tico Tico (Fonte: 0 autor,2018).

a) Lucia (1981) desenvolveu um modelo de predição de espalhamento bidimensional da lama que apresenta um enfoque inteiramente diferente do modelo de fluxo de fluído. Conhecido como modelo de equilíbrio de forças, admite que no momento em que o fluxo de lama atinge a situação de repouso, a resistência ao cisalhamento não drenada do rejeito ao longo de sua base é igual à resistência requerida para a ocorrência de equilíbrio estático. 0 mesmo calculou esta resistência, com os resultados de retro análise, a partir da configuração final do rejeito, após a ruptura, em 14 casos históricos;

b) Jeyapalan, Duncan e Seed (1983) avaliaram a distância de inundação gerada fluxo de 
depósitos de rejeitos a partir de parâmetros de resistência usando métodos computacionais. O fluxo foi avaliado em regime laminar e os rejeitos liquefeitos se comportaram aproximadamente como um fluido plástico Bingham, exibindo características de tensão de escoamento e fluxo viscoso assim que essa tensão fosse excedida;

c) Pastor et al. (2002) estabeleceram um modelo integrado para simulação dos fluxos de lama e detritos que são causados pela falha de barragens de rejeito, depósitos de lixo de mineração e outras estruturas similares, onde a massa deslizante é determinada usando um código de elemento finito elastoplástico acoplado e uma equação constitutiva adequada. Neste modelo, quando a falha é disparada, a propagação do material mobilizado é analisada considerando as propriedades do fluxo calculadas sobre a profundidade;

d) Lazarim (2015) estabeleceu uma previsão de espalhamento de rejeito mineral de ferro em cenários controlados, a partir de modelos físicos, com uso de um modelo numérico baseado no método dos taludes infinitos, variando parâmetros, como $S_{u}$ e inclinação da superfície à jusante da barragem de rejeitos.

\section{ASPECTOS REFERENTES AO VOLUME E DEPOSIÇÃO DO REJEITO NA RUPTURA}

Neste tópico serão anunciados os estudos referentes a estimativas de materiais liberados após um evento de ruptura de barragens de rejeitos e dados referentes a deposição do rejeito mineral nas mesmas condições.

\subsection{Volume de material liberado}

Rico, Benito e Diez-Herrero (2008) citaram uma limitação importante para a aplicação desta equação à análise de risco de barragens de rejeitos consiste na incerteza do possível volume de saída de rejeitos no caso de falha. Os mesmos sugeriram uma relação empírica considerando o volume de armazenamento de rejeitos $\left(V_{\text {Lib. }}\right)$ e os rejeitos liberados nos incidentes ( $\left.V_{\text {Reserv. }}\right)$, que tem na equação (10).

$\mathrm{V}_{\text {Lib }}=0,354 \times \mathrm{V}_{\text {Reserv }}{ }^{1,01}$

A equação (1) possui $r^{2}=0,86$ e mostra que, em média, um terço dos rejeitos e da água na lagoa de decantação é liberado durante as falhas da barragem. A curva de envoltória representa o volume máximo de rejeitos que pode ser liberado na situação mais extrema em que o volume da lagoa foi esvaziada após a ruptura da barragem, como é o caso de acidentes com barragens de armazenamento de água ou de tanques industriais (diluídos).

Vick (1991) estimou transferência de massa de rejeitos pós ruptura a partir do estudo de 32 barragens, considerando os rejeitos em estado saturado e produzidos por moagem ou processos de concentração. A partir de uma análise estatística, o histograma aproximou-se com a fidelidade de uma curva de distribuição normal, com média $\left(m_{y}=0,193\right)$ e desvio padrão $\left(\sigma_{\text {Lny }}=\right.$ $0,735)$, obtendo a estimativa do volume liberado pela equação (11):

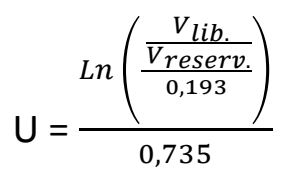

Onde: 
U: Variável normal estandardizada;

$V_{L i b .:}$ Volume liberados de rejeitos pós-ruptura;

$V_{\text {Reserv.: }}$ Volume do reservatório de rejeitos.

A curva da probabilidade de ruptura em função da $\left(\frac{V_{\text {lib. }}}{V_{\text {reserv. }}}\right)$ está anunciada na Figura 19.

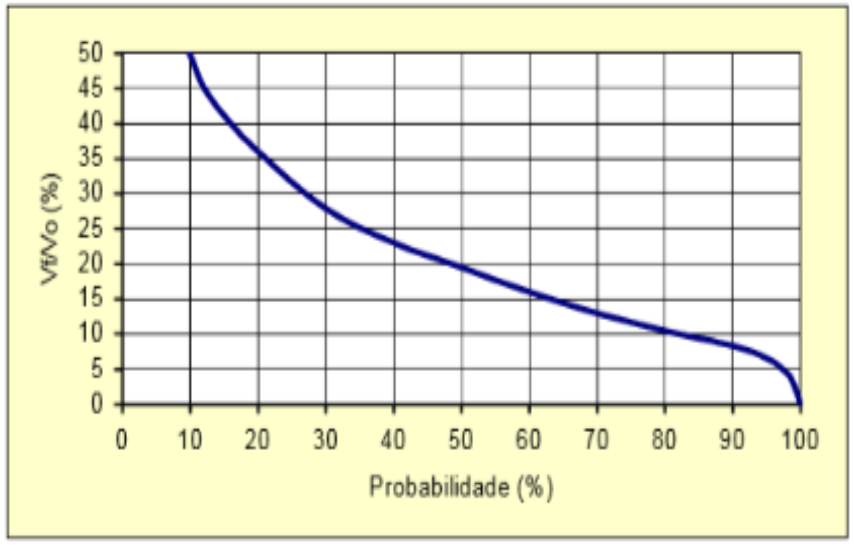

Figura 19: Probabilidades das porcentagens de volume de rejeitos que será liberada na ruptura de barragens (Fonte: Vick, 1991).

\section{2 Ângulo de deposição do rejeitos pós-ruptura}

Alguns casos históricos indicam que o cone de depressão da massa de rejeitos remanescente da ruptura da barragem de rejeitos se forma com ângulos de $3,5^{\circ}$ a $6^{\circ}$. (Martin, Fontaine e Cathchart, 2015). Enquanto os rejeitos saturados liquefeitos estabilizam-se a jusante nas encostas de $1^{\circ}$ a $4^{\circ}$ (Lucia, 1981), com a deposição dos rejeitos em grande parte dependendo da reologia de rejeitos, topografia a jusante e encostas.

\section{CONSIDERAÇÕES FINAIS}

Segundo os resultados das simulações em modelo físico, foram desenvolvidas as seguintes considerações:

1) Devido ao grande vulto de material processados na fase de lavra e beneficiamento, dentre as técnicas existente, as barragens de mineração ainda são consideradas as técnicas mais viáveis do ponto de vista técnico-econômico;

2) É necessário que exista monitoramento e controle com um determinado nível de periodicidade afim de prever comportamentos de deformação da barragem;

3) Por mais que ainda existam ferramentas computacionais com software de modelagens baseado em MEF, evolução tecnológica de dispositivos de instrumentação, modernização de métodos construtivos, ensaios de laboratório, técnicas de controle e monitoramento aliadas legislações rígidas de âmbito estadual e federal ainda é comum se deparar com casos de rupturas de barragens de rejeitos;

4) Até então não existem modelos numéricos compatíveis com o fenômeno de ruptura 
de barragens de rejeitos. Estas barragens, quando rompidas transferem milhares de metros cúbicos de materiais e que as simulações se baseiam em aspectos hidrodinâmicos. Entretanto, o cada rejeito apresenta um comportamento diferente em relação as suas propriedades físico-químicas e que consequentemente torna complexa a avaliação de liberação e espalhamento.

\section{AGRADECIMENTOS}

Os autores prestam seus agradecimentos à CAPES (Coordenadoria de Aperfeiçoamento de Pessoal Nível Superior), pelo fomento à pesquisa; ao PPGEC (Programa de Pós-Graduação de Engenharia Civil) da UFRGS, pela infraestrutura e auxílio técnico-científico.

\section{REFERÊNCIAS}

Aguiar, D. P. de O. (2014) Contribuição ao estudo do índice de segurança de Barragens (Dissertação de Mestrado). Faculdade de Engenharia, Arquitetura e Urbanismo - UNICAMP, São Paulo, SP, Brasil, 146p.

AKW. Disponível em: http://www.akwauv.com/Hidrociclones-AKA-VORTEX-e-distribuidoresradiais-AKA-SPIDER.htm. Acesso em: 15 Mai. 2018.

Alberruche, E.; González. J. C. A.; Pacheco, R. L. R.; Vadillo, L.; Gomez, V. R. \& Naranjo, F. J. F. M. (2016). Simplified guide for closed/abandoned mining waste facilities risk assessment.Madrid: Ministério de agricultura y pesca, alimentación y médio ambiente, 208p.

Alsharedah, Y. A. (2015) Slope Stability Enhancement of an Upstream Tailings Dam: Laboratory Testing and Numerical Modelling (Dissertation of Master). Program in Civil and Environmental Engineering, University of Western Ontário, Ontário, Canadá,146p.

ANA (2017). Relatório de segurança de barragens. Brasília: Agência Nacional de águas, 229p. Recuperado de http://www.snisb.gov.br/portal/snisb/relatorio-anual-de-seguranca-debarragem/rsb-2016/relatorio-de-seguranca-de-barragens-2016.pdf.

Araújo, C. B. (2006). Contribuição ao Estudo do Comportamento de Barragens de Rejeito de Mineração de Ferro (Dissertação de mestrado). Programa de Pós-Graduação de Engenharia UFRJ, Rio de Janeiro, RJ, Brasil, 133p.

ABNT NBR 13028, de 30 de Agosto de 1993. Elaboração e apresentação de projeto de disposição de rejeitos de beneficiamento, em barramento, em mineração. Rio de Janeiro: Associação Brasileira de Normas Técnicas.

ABNT NBR 13028, de 14 de Novembro de 2017. Associação Brasileira de Normas Técnicas (2017). Mineração - Elaboração e apresentação de projetos de barragens para disposição de rejeitos, contenção de sedimentos e reservação. Rio de Janeiro: Associação Brasileira de Normas Técnicas.

Ávila, J. P. e Sawaya, M. (2011). As barragens de rejeitos no Brasil: Sua evolução nos últimos 
anos. In De Mello, F. M. \& Piasentin, C. (Orgs). História das barragens do Brasil: Séc. XIX, Séc XX e Séc. XXI. (1a ed., s/cap., pp.369-395). Rio de Janeiro, Brasil: CBDB, 524p.

Ávila, J. P. (2012) Barragem de rejeitos no Brasil. Rio de Janeiro: CBDB, 166p.

Australian Government Department of Industry (2016) Leading Practice Sustainable Development Program for the Mining Industry. Australia: Australia government, 118p.

Azam, S; Li, Q. (2010). Tailings Dam Failures: A Review of the Last One Hundred Years. Geotechnical news, pp. 50-53.

Beier, N. A. (2015). Development of a Tailings Management Simulation and Technology Evaluation Tool. (Tese de doutorado). Department of Civil and Environmental Engineering, University of Alberta, Alberta, Canadá, 454p.

Bhanbhro, R. (2014) Mechanical Properties of Tailings: Basic Description of a Tailings Material from Sweden (Tese de Doutorado). Department of Civil, Environmental and Natural Resources Engineering, Lulea University of Technology, Lulea, Suécia,53p.

Bing, H. (2014). Numerical Simulation Analysis of Tailings Dam Heightening Expansion Stability. Applied Mechanics and Materials, 670-671, pp. 1079-1082. doi:org/10.4028/www.scientific.net AMM.670-671.1079

Bjelkevik, A. \& Knutsson, S. (2005, july) Swedish tailings-comparison of mechanical properties between tailings and natural geological materials. Proceedings securing the future, International Conference on Mining and the Environment Metals and Energy Recovery, Stockholm, Swenden, pp. $117-129$.

Blight, G. E. \& Bentel, G. M. (1983, April). The behaviour of mine tailings during hydraulic deposition. Journal of the South African Institute of minning and metallurgy, Johannesburg, South Africa, 85, pp 73-86.

Blight, G. E \& Fourie, A. B. (2015) A review of catastrophic flow failures of deposits of mine waste and municipal refuse. Recuperado em https://www.researchgate.net/publication/242193591_A_REVIEW_OF_CATASTROPHIC_FLOW _FAILURES_OF_DEPOSITS_OF_MINE_WASTE_AND_MUNICIPAL_REFUSE?enrichld=rgreq4bdd2b1852542378663c820ecc400d30-

XXX\&enrichSource $=$ Y292ZXJQYWdIOzIOMjE5MzU5MTtBUzoxMTQ2NTYYNzQyOTI3MzhAMTQw NDMONzU5NTc3MQ\%3D\%3D\&el=1_x_2\&_esc=publicationCoverPdf. Acesso em: 22 de Mai de 2018.

Bradley, D. (1965) The Hydrocyclone - 1st Edition, UK: Permamon Press, 348p.

Ávila, J. P. \& Sawaya, M. (2011). As barragens de rejeitos no Brasil: Sua evolução nos últimos anos. In De Mello, F. M. \& Piasentin, C. (Orgs). História das barragens do Brasil: Séc. XIX, Séc XX e Séc. XXI. (1a ed., s/cap., pp.369-395). Rio de Janeiro, Brasil: CBDB, 524p. 
Carriso, R. C. C. \& Correia, J. C.G. (2004). Classificação e Peneiramento. In Luz, A.U.; Sampaio J. A.; França, S. C. A. (Orgs). Tratamento de Minérios. (5a ed., Cap. 6, pp.257-296). Rio de Janeiro, Brasil: Cetem, 867p.

Cambridge, M.; Ferguson, G.; Coppin, N.; Molloy, C. \& Czajewski, K. (2018). Engineering Design. In Cambridge, M. (Org.). The Hydraulic Transport and storage of extractive waste. (s/ed., Cap. 3, pp. 9-31). Cham, Switzerland: Springer, 388p.

CNDH (2017). Relatório sobre o rompimento da barragem de rejeitos da mineradora Samarco e seus efeitos sobre o vale do rio doce. Brasília: Agência Nacional de águas, 59p. Recuperado de http://www.mdh.gov.br/informacao-ao-cidadao/participacao-social/old/cndh/relatorios/ RelatriodaBarragemdoRioDoce_FINAL_APROVADO.pdf

Consoli, N. C. (1991). Numerical modelling of the sedimentation and consolidation of tailings (Tese de Doutorado). Department Civil Engineering. Concordia University, Concórdia, Canadá, $163 p$.

D’Agostino, L. F. (2008). Praia de barragens de rejeitos de mineração: características e análise da sedimentação (Tese de doutorado). Escola Politécnica, Universidade de São Paulo, São Paulo, Brasil, 374p.

Davies, M. P. (2002). Tailings Impoundment Failures: Are Geotechnical Engineers Listening?. Geotechnical news, pp. $31-36$.

Duarte, A. P. (2008). Classificação das barragens de contenção de rejeitos de mineração e de resíduos industriais no estado de minas gerais em relação ao potencial de risco (Dissertação de Mestrado). Programa de Pós-graduação em saneamento, meio-ambiente e recursos hídricos, Universidade Federal de Minas Gerais, Minas Gerais, Brasil, 114p.

DNPM (2018). Recuperado de http://www.dnpm.gov.br/dnpm/sumarios/sumario-mineral-2015. Acesso em: 25 Mar. 2018.

Dunnicliff, J. (1988) Geotechnical Instrumentation for Monitoring Field Performance. EUA: Ed. John Wiley and Sons, 577p.

Espósito, T. de J. (2000). Metodologia probabilística e observacional aplicada a barragens de rejeitos construídas por aterro hidráulico. Tese de Doutorado, Departamento de Engenharia Civil e Ambiental, Universidade Federal de Brasília, Brasília, Brasil, 363p.

Fell, R.; Macgregor. P.; Stapledon, D.; Bell, G. \& Foster, M. (2015). Geotechnical engineering of dams (2 edition). Leiden: CRC Press/Balkema, 1348p.

Fitton, T. G.; Bhattacharya, S. N. \& Chryss, A. G. (2008, December). Three - dimensional modeling of tailings beach shape. Computer -aided civil and infrastructure engineering, Ohio, United States, 23, pp. 31-44. doi:.org/10.1111/j.1467-8667.2007.00519.x 
Fundaoinvestigation (2018) Investigação da barragem de rejeitos do fundão. Recuperado de: http://fundaoinvestigation.com/pt-br/video-presentation/. Acesso em: 23 de Out de 2018.

Gaioto, N. (2003) Introdução ao projeto de barragens de terra e de enrocamento. São Carlos: Ed. USP São Carlos, Brasil, 126p.

Gerscovich, D. M. S. (2012) Estabilidade de taludes. São Paulo: Oficina de textos, Brasil, 166p.

Haile, J. P. \& Brouwer, K. J. (1994, August). Modified Centerline construction of tailings embankments. International Conference on Environmental Issues and Waste Management in Energy and Mineral Production, Perth, Western Australia, Australia,3, pp.1-7.

Hassellund, L.; Knutsson, R.; Mattsson, H. \& Knutsson, S. (2016, May) Numerical analysis of an upstream tailings dam. Proceedings of the Nordic Geotechnical Meeting. Reikjavik, Island, 17, pp.727-736.

Hallman, D. S. \& Dorey, R. (1995). Mine Tailings Deposition Practices, Liquefaction Potential and Stability Implications. International Conferences on Recent Advances in Geotechnical Earthquake Engineering and Soil Dynamics, St. Louis, Missouri, USA, 2, pp. 451 - 456.

Hernandez, H. M. O. (2002). Caracterização geomecânica de rejeitos aplicada a barragens de aterro hidráulico (Dissertação de Mestrado). Faculdade de tecnologia, Universidade Federal de Brasília, Brasília, Brasil, 174p.

Hu, L.; Wu, H.; Zhang, L.; Zhang, P. \& Wen, Q. (2017, February) Geotechnical Properties of Mine Tailings. Journal Materials in Civil Engineering. London, United Kingdom, 29 (2), pp.1-10. doi:.org/10.1061/(ASCE)MT.1943-5533.0001736

IBM (1995). Tailings dams design, Boletim 30. Recuperado de https://ibm.gov.in/writereaddata/files/09292016112123Tailings\%20dam\%20design.pdf

ICOLD (2001). Tailings dams risk of dangerous ocurrences: Lessons learnt from pratical experiences, Boletim 121. Recuperado de http://www.unep.fr/shared/publications/pdf/2891TailingsDams.pdf

Jeyapalan, J. K.; Duncan, J. M. \& Seed, H. B. (1983, December). Investigation of flow failures of tailings dams. Journal of Geotechnical Engineering, Vancouver, Canada, 109 (2), pp. 172-189. doi:.org/10.1061/(ASCE)0733-9410(1983)109:2(172)

Jiabin, X.; Jing, F.; Zhiliang, W.; e Wenlian, L. \& Jingyou, H. (2013) Numerical simulation on the three-dimensional seepage field of Zhelamuqing tailings dam. Advances in materials science and engineering. London, United Kingdom, 256-259, pp.19-25. doi:.org/10.4028/www.scientific.net/AMM.256-259.19

Jun, H.; Suo, A. L. \& Quan, W. Z. (2009, October). Study on Application and Operation Optimization of Hydrocyclone for Solid-liquid Separation in Power Plant. Proceedings of the World Congress on Engineering and Computer Science, São Francisco, EUA, 1, pp 1-6. 
Knight, R.B. \& Haile, J.P. (1983, June). Sub-Aerial Tailings Deposition. Proceedings of the Panamerican Conference on Soil Mechanics and Foundation Engineering, Vancouver, Canada, 7, pp 627-639.

Kossof, D.; Dublin, W. E.; Alfredsson, M.; Edwards, S. J.; Macklin, M. G. \& Hudson-Edwards, K. A. (2014, December). Mine Tailings Dams: Characteristics, Failure, environmental impacts and remediation. Applied Geochemistry, Vancouver, Canada, 51, pp 229-245. doi:.org/10.1016/j.apgeochem.2014.09.010

Lazarim, T. P (2015). Espalhamento de rejeitos em cenários de ruptura de barragens - Simulações em modelo reduzido e proposta de avaliação de área atingida (Dissertação de Mestrado). Programa de Pós-graduação em Engenharia Civil, Universidade Federal do Paraná, Paraná, Brasil, 120p.

Lei n. 12334, de 20 de setembro 2010. Estabelece a Política Nacional de Segurança de Barragens destinadas à acumulação de água para quaisquer usos, à disposição final ou temporária de rejeitos e à acumulação de resíduos industriais, cria o Sistema Nacional de Informações sobre Segurança de Barragens e altera a redação do art. 35 da Lei no 9.433, de 8 de janeiro de 1997, e do art. 4o da Lei no 9.984, de 17 de julho de 2000. Recuperado de http://www.planalto.gov.br/ccivil_03/_ato2007-2010/2010/lei/l12334.htm

Linghthall, P. C.; Watts, B.D. \& Rice, S. (1989). Deposition Methods for construction of Hydraulic fill Tailings Dams. Vancouver Geotechnical Society Syposium Program, Vancouver, Canada, 4, pp 1- 15.

Lindquist, L. N. \& Cruz, P. T. (1996) Instrumentação. In Cruz; P. T (Org.). 100 barragens brasileiras: caso históricos, materiais de construção, projeto (2a.ed., cap. 19, pp. 606-647). São Paulo: Oficina de textos.

Lozano, F. A. E. (2006). Seleção para locais de barragens de rejeitos usando o método de análise hierárquica (Dissertação de Mestrado). Departamento de engenharia de estruturas e fundações, Universidade de São Paulo, São Paulo, Brasil, 128p.

Lucia, P. C. (1981). Review of experiences with flow failures of tailings dams and waste impoundments (Thesis of Doctoral), University of Berkeley, Berkeley, USA, 223p.

Luz, A. B. \& Lins, F. A. F. (2004). Introdução ao tratamento de minérios. In L Luz, A.U.; Sampaio J. A.; França, S. C. A. (Orgs). Tratamento de Minérios. (5a ed., Cap. 1, pp.3-18). Rio de Janeiro, Brasil: Cetem, 867p.

Marcus, J. J. (1997). Mining environmental handbook: Effects of Mining on the Environment and American Environmental Controls on Mining. London. England: World Scientific Publishing, $816 \mathrm{p}$.

Martin, V.; Fontaine, D. \& Cathcart, J. (2015, October) Challenges with conducting tailings dam breach studies. Proceedings of Tailings and Mine Waste Conference. Vancouver, Canada, pp. 


\section{4-328.}

McPhail, G.I., and Wagner, J.C. (1987) Disposal of residues. In Stanley, G. G (Org) The Extractive Metallurgy of Gold in South Africa, The Chamber of Mines of South Africa. (Vol. 2, Cap.11 pp.655-707). Johannesburg, Soul Africa: SAIMM, 608 p.

Melentiev, V.A., Kolpashnikov, N.P. and Volnin, B.A. (1973) Hydraulic Fill Structures. Energyia, Moscow (in Russian).

Milonas, J. G. (2006). Análise do processo de reconstituição de amostras para caracterização do comportamento de barragens de rejeitos de minério de ferro em aterro hidráulico (Dissertação de mestrado). Faculdade de Tecnologia, Universidade de Brasília, Brasília, Brasil, 146p.

MIN (2002). Manual de segurança inspeção e de barragens. Ministério da integração nacional: Brasília, Brasil,148p. Recuperado de http://www.mi.gov.br/documents/10157/3678963/Manual+de+Seguranca+e+Inspecao+de+B arragens.pdf/fa0407aa-6332-42b8-9bad-a1609bd87dfc

Moretti, M. R. \& Cruz, P. T. (1996) Aterros hidráulicos e sua aplicação na construção de barragens. In Cruz; P. T (Org.). 100 barragens brasileiras: caso históricos, materiais de construção, projeto (2 ${ }^{a}$ ed., cap.17, pp. 555-590). São Paulo: Oficina de textos.

Morris, P. H. (2004). Mine Waste Beach Profile and Flow Resistance Equations. International Journal of surface mining, London, United Kingdom, 18 (4), pp. 253-272. doi.org/10.1080/1389526042000263315

Morris, P. H.; Lockington, D. A. \& Apelt, C. J. (2000, May). Correlations for mine tailings consolidation parameters. International Journal of surface Mining,14(3), pp. 171-182. doi:.org/10.1080/13895260008953321

Mular, A. L; Halbe, D.N. \& Barratt, D. (2002) Mineral Processing Plant Design, Practice and Control; Proocedings Vol.2 - 1 ed., SME: Littleton, Colorado, USA, 2394 p.

Niguyen, Q.; Borger, D. (1998, April) Application of rheology to solving tailings disposal problems. International Journal of Mineral Process. Adelaide, Australia, Vol. 54 (3-4), pp.217-233. doi:. .org/10.1016/S0301-7516(98)00011-8

Oliveira; W. L \& Abrão, P. (2015). Disposição de rejeitos de mineração. In Zuquette, L. V (Org). Geotecnia Ambiental. (1a ed., pp. 263-306). Rio de Janeiro: Elsevier,399p.

Ormann, L.; Zardari, M. A.; Mattsson, H.; Bjelkevik, A. \& Knutsson, S. (2013, April) Numerical analysis of strengthening by rockfill embankments on an upstream tailings dam. Canadian Geotechnical Journal. Ontario, Canada, Vol. 50 (4), pp.1-9. doi:.org/10.1139/cgj-2012-0255

Parker, G., Paola, C., Whipple, K.X. \& Mohrig, D. (1998, October) Alluvial Fans Formed by Channelised Fluvial and Sheet Flow. I: Theory. Journal of the Hydraulics Division - Civil Engineering Database. 124(10), pp. 985-995. doi:.org/10.1061/(ASCE)0733- 
9429(1998)124:10(985)

Pastor, M.; Quecedo, M.; Fernandez Merodo, J. A.; Herrores, M. I.; Gonzalez, E. \& Mira, P. (2002, October) Modelling tailings dams and mine waste dumps failures. Geotechnique. London, United Kingdom, 52 (8), pp. 579-591. doi:.org/10.1680/geot.2002.52.8.579

Portaria DNPM no 70389, de 17 de Maio de 2017. Cria o Cadastro Nacional de Barragens de Mineração, o Sistema Integrado de Gestão em Segurança de Barragens de Mineração e estabelece a periodicidade de execução ou atualização, a qualificação dos responsáveis técnicos, o conteúdo mínimo e o nível de detalhamento do Plano de Segurança da Barragem, das Inspeções de Segurança Regular e Especial, da Revisão Periódica de Segurança de Barragem e do Plano de Ação de Emergência para Barragens de Mineração. Recuperado de http://www.dnpm.gov.br/portaria-dnpm-no-70-389-de-17-de-maio-de-2017-seguranca-debarragens-de-mineracao

Portes, A. M. C. (2013). Avaliação da disposição de rejeitos de minério de ferro nas consistências polpa e torta. Dissertação de Mestrado, Escola de Engenharia, Universidade Federal de Minas Gerais, Minas Gerais, Brasil, 154p.

Qiu, Y. \& Sego, D. C. (2001, February) Laboratory properties of mine tailings. Canadian Geotechnical Journal. 38(1), pp.183-190. doi:.org/10.1139/t00-082

Resolução Conama no 237, de 19 de novembro de 1997. Regulamenta os aspectos de licenciamento ambiental estabelecidos na Política Nacional do Meio Ambiente. Recuperado de http://www.mma.gov.br/port/conama/legiabre.cfm?codlegi=237

Ribeiro, L. F. M. (2000). Simulação física do processo de formação dos aterros hidráulicos aplicado a barragem de rejeitos (Tese de doutorado). Departamento de Engenharia Civil e Ambiental, Universidade de Brasília, Brasília, Brasil, 235p.

Rico, M.; Benito, G. \& Díez-Herrero, A (2008,June). Floods from tailings dam failures. Journal of Hazardous Materials, 154 (1-3), pp. 79-87. doi:.org/10.1016/j.jhazmat.2007.09.110

Rico, M.; Benito, G.; Salgueiro, A.R; Díez-Herrero, A \&Pereira, H.G. (2008, April). Reported tailings dam failures: the european incidents in the worldwide context. Journal of Hazardous Materials, 152(2), pp. 846-852. doi:.org/10.1016/j.jhazmat.2007.07.050

Saad, Z. \& Mitri, Y.(2011, January). Hydromechanical Analysis of Upstream Tailings Disposal Facilities. Journal of Geotechnical and Geoenvironmental Engineering, Vancouver, Canada, 137 (1), pp 27-42. doi:.org/10.1061/(ASCE)GT.1943-5606.0000403

Santos, A. G. \& Ribeiro, L. M. F. (2007, Setembro). Condutividade hidráulica saturada de um rejeito de minério de ferro. Revista Escola de Minas, Minas Gerais, Brasil, 60 (3), pp. 465-470. doi:.org/10.1590/S0370-44672007000300005.

Santos, N. M. \& Meyer, P. (1980). A previsão da segregação granulométrica em aterros hidráulicos. Seminário nacional de grandes barragens, Rio de Janeiro, Brasil, 13, pp. 473- 493. 
Sarsby, R. (2000) Enviromental Geotechnics. London: Thomas Telford Publishing: London, 600p.

Shamsai, A.; Pak, A., Bateni, S. M. \& Ayatollahi A. H. (2007, October). Geotechnical Characteristics of Copper Mine Tailings: A Case Study. Geotechnical and geological engineering, 25 (5), pp. 591- 602. Doi:.org/10.1007/s10706-007-9132-9

Soares, L (2010). Barragem de rejeitos. In: Luz, A.U.; Sampaio J. A.; França, S. C. A. (Orgs). Tratamento de Minérios. (5a ed., Cap. 19, pp. 831-888). Rio de Janeiro, Brasil: Cetem, 867p.

Silveira, J.F.A. (2006) Instrumentação e segurança de barragens de terra e enrocamento. São Paulo: Oficina de textos, 416p.

Svarovsky; L. \& Thew, M. T. (1992). Hydrocyclones: Analisys and Applications. England: Kluwer Academic Publishers, 440p.

Wang, C.; Harbottle, D.; Liu, Q.; Xu, Z. (2014, April) Current state of fine mineral tailings treatment: A critical review on theory and practice. Mineral Engineering. Alberta, Canada, Vol. 58, pp.113-131. doi:.org/10.1016/j.mineng.2014.01.018 